Article

\title{
Irrigation Water Allocation at Farm Level Based on Temporal Cultivation-Related Data Using Meta-Heuristic Optimisation Algorithms
}

\author{
Bahram Saeidian ${ }^{1}$, Mohammad Saadi Mesgari ${ }^{2}$, Biswajeet Pradhan ${ }^{3,4, *(D)}$ and \\ Abdullah M. Alamri 5 \\ 1 GIS Division, Faculty of Geodesy and Geomatics, K. N. Toosi University of Technology, Tehran 19967-15433, \\ Iran; Bahram_saeidian@yahoo.com \\ 2 GIS Division, Faculty of Geodesy and Geomatics, and Geoinformation Technology Center of Excellence, K. \\ N. Toosi University of Technology, Tehran 19967-15433, Iran; mesgari@kntu.ac.ir \\ 3 Centre for Advanced Modelling and Geospatial Information Systems (CAMGIS), Faculty of Engineering and \\ IT, University of Technology Sydney, Sydney, NSW 2007, Australia \\ 4 Department of Civil Engineering, Indian Institute of Technology Indore (IITI), Khandwa Road, Simrol, \\ Indore 453552, India \\ 5 Department of Geology \& Geophysics, College of Science, King Saud University, P.O. Box 2455, \\ Riyadh 11451, Saudi Arabia; alamri.geo@gmail.com \\ * Correspondence: Biswajeet.Pradhan@uts.edu.au; Tel.: +61-2-9514-7937
}

Received: 23 October 2019; Accepted: 6 December 2019; Published: 11 December 2019

check for updates

\begin{abstract}
The present water crisis necessitates a frugal water management strategy. Deficit irrigation can be regarded as an efficient strategy for agricultural water management. Optimal allocation of water to agricultural farms is a computationally complex problem because of many factors, including limitations and constraints related to irrigation, numerous allocation states, and non-linearity and complexity of the objective function. Meta-heuristic algorithms are typically used to solve complex problems. The main objective of this study is to represent water allocation at farm level using temporal cultivation data as an optimisation problem, solve this problem using various meta-heuristic algorithms, and compare the results. The objective of the optimisation is to maximise the total income of all considered lands. The criteria of objective function value, convergence trend, robustness, runtime, and complexity of use and modelling are used to compare the algorithms. Finally, the algorithms are ranked using the technique for order of preference by similarity to ideal solution (TOPSIS). The income resulting from the allocation of water by the imperialist competitive algorithm (ICA) was 1.006, 1.084, and 1.098 times that of particle swarm optimisation (PSO), bees algorithm (BA), and genetic algorithm (GA), respectively. The ICA and PSO were superior to the other algorithms in most evaluations. According to the results of TOPSIS, the algorithms, by order of priority, are ICA $\mathrm{PSO}, \mathrm{BA}$, and GA. In addition, the experience showed that using meta-heuristic algorithms, such as ICA, results in higher income (4.747 times) and improved management of water deficit than the commonly used area-based water allocation method.
\end{abstract}

Keywords: agriculture; irrigation; water allocation; optimisation; meta-heuristic algorithm; GIS

\section{Introduction}

Most countries face a water scarcity problem. In many countries, including Iran, the main part of the water supply is used for agriculture [1-5]. During drought years, the provision of agricultural water is considered a lower priority than that of urban and industrial water. Therefore, proper planning for the use of agricultural water resources is necessary $[2,4,6,7]$. In many countries, optimal allocation 
of water (AW) is regarded as part of a sustainable development policy $[3,8]$. In $\mathrm{AW}$, the decision-maker defines the share of each user, considering limitations such as attainable sources of water and various objectives such as income maximisation [9].

In light of the water shortage at different times and places, the AW has been the subject of many studies. Most of these studies focus on larger scales, including different users (such as agriculture and industries), basins, networks, sub-regions, and crops (according to the area covered by each crop type in the entire region). Divakar et al. [10] and Babel et al. [11] worked on the AW to the agriculture, industry, power generation, service, and other sectors, with economical income as the objective function. Chang et al. [12] allocated water to different users with respect to the estimated amount of water scarcity. Wang et al. [13] predicted the needed water and allocated it optimally to different sections such as agriculture and industry. A study by Song et al. [14] determined the AW attainable from various sources (surface, underground, and others) to different consumers and areas for 2015 and 2020. Davijani, Banihabib, Anvar, and Hashemi [9] optimised the AW and planting area for any crop. Rees et al. [15], Schlüter et al. [16], and McKinney et al. [17] considered the AW to different basins. Yazdi et al. [18] allocated water to irrigation networks. Shangguan et al. [19] measured the AW to networks and sub-regions and crops of each network or sub-region. Dai and Li [2] conducted AW to different crops at the sub-region level. Vaghefi et al. [20] allocated water to different sections of the study area for different cropping pattern scenarios. Niu et al. [21] also allocated water to three crops in different sub-areas with different scenarios; then, they found optimised crop area patterns for different crops in each sub-area. Li et al. [22] and Li and Guo [3] allocated water to various crops in different conditions such as wet and dry cultivation years.

In the aforementioned studies, the AW is conducted in macro scale to serve macro-level policies. In such a scale, it is not possible to consider factors such as the crop type and growth stage of each land (based on the cultivation date) and the crop response to water shortage in that stage. In fact, lands with identical crop types but different planting dates have different water needs and water deficit responses. To include such factors, we need to optimise the AW in land scale. Other studies have been conducted at the farm level. However, they concentrate on changing and improving the cultivation pattern. Alvarez, de Juan Valero, Martín-Benito, and Mata [1] proposed changes in cropping patterns and crop types at the farm level with regard to the available water. In addition, Montazar and Rahimikob [23], Reca et al. [24], and Kuo et al. [25] changed the cropping pattern and crop types in different spatial units, considering several constraints including water deficit. The main limitation of these studies is that after estimating the available water, they proposed crop changes for the coming years. In fact, these studies are not focused on the AW to cultivated lands.

In the present study, after estimating the available water, the AW at farm level is optimised, considering the type and growth stage of the crops on each land. In such conditions, the AW can be considered a complex optimisation problem due to the complexity and nonlinearity of the objective function and other influencing parameters. Numerous states (solutions) are possible for the AW to different users, and any such solution satisfies objectives differently. With these, the AW can be considered an optimisation problem in which allocation scenarios are taken as solutions and various demands are regarded as objectives and constraints. This condition involves numerous possible solutions and heavy computations regarding objective functions and constraints. Usually, meta-heuristic methods are used to solve such complex optimisation problems. In this study, the AW to agricultural farms is represented as an optimisation problem and solved using the meta-heuristic algorithms of genetic algorithm (GA), particle swarm optimisation (PSO), bees algorithm (BA), and imperialist competitive algorithm (ICA), and finally, the adequacy of algorithms is compared. In the rest of this section, research on the use of these four algorithms in agriculture and AW are reviewed.

Among others, the PSO and GA algorithms are often used in water resource management and allocation problems and are a good basis for comparison and evaluation of other algorithms. In many studies such as [25-32], GA is used for those issues. Similarly, in some studies such as [9,33-40], the PSO algorithm is used for the same problems and showed the adequacy of this algorithm. Chang et al. [41] 
and Huang et al. [42] used the GA-PSO hybrid algorithm for the optimal management of water resources. Davijani, Banihabib, Anvar, and Hashemi [9] compared the use of PSO and GA algorithms for allocating water to agricultural, industrial, and municipal consumptions over one year.

The ICA is successfully used in a variety of applications related to industrial, civil, mechanical, electrical, and computer engineering [43]. Hosseini-Moghari et al. [44] used this algorithm for water resource management. Karamouz et al. [45] compared the suitability of the ICA and PSO algorithms for allocating reservoir water to agricultural, industrial, and urban consumers. Many studies have used the BA for various applications [46]. However, to the best of our knowledge, it is not used in AW.

Considering the preceding review on the use of these algorithms in water resource management and other applications, the reasons for selecting GA, BA, ICA, and PSO algorithms in this study are as follows: (1) They are among the most commonly used meta-heuristic algorithms. (2) On similar problems, the performance of these algorithms was acceptable. (3) The solution space of this study is continuous, while the ICA and PSO are inherently continuous, and GA and BA are also applicable to continuous issues.

The aim of this study is to model the AW to farms as an optimisation problem and solve it using some meta-heuristic algorithms. In the allocation model, the data related to the types and growth levels of the crops are considered. A second objective is to compare the performance of those algorithms for the considered problem.

\section{Method and Materials}

In this section, the methods used along with the data and study area are described.

\subsection{Method}

The flowchart in Figure 1 shows the main steps in the study. First, the data are collected and prepared. These tasks include creating farm maps and their attribute data (crop type and planting date), gathering the data needed to estimate water needs (rainfall, crop coefficient, and others), and the data needed to calculate objective function (crop cost and price, yield response factor, and others). Using the spatial analysis functions of geographic information system (GIS), farms with identical crop type and growth stage are merged. In the next stage, for each farm, crop water requirement and irrigation water requirement (i.e., farm requirements) are calculated using their crop type, planting date, stage of crop development, and other parameters. The sum of irrigation water requirements for all farms is the total required water. Then, the water entered in the area from all sources is estimated. If the amount is lower than the total required water, then the attainable water should be allocated by the algorithm. In another stage, the optimisation of the farm-water allocation is modelled. The objective function, which is to be maximised by the algorithms, is defined as the total economic profit attained from all farms. It is calculated on the basis of farm area, water production function, and crop prices. The allocation procedure is designed such that instead of the water itself, the water deficit is distributed among the lands, on the basis of parameters such as crop type, crop growth period, land area and water production function.

Thereafter, the developed model is implemented using each algorithm considering the farms' water requirements and attainable water. The implementation results of the four algorithms are compared using criteria of best-achieved objective function, convergence rate, repeatability, runtime, and complexity of modelling. The TOPSIS method is used to select the best algorithm considering all criteria. Finally, the results of the selected algorithm are compared with those of a general AW method based on farm areas. 


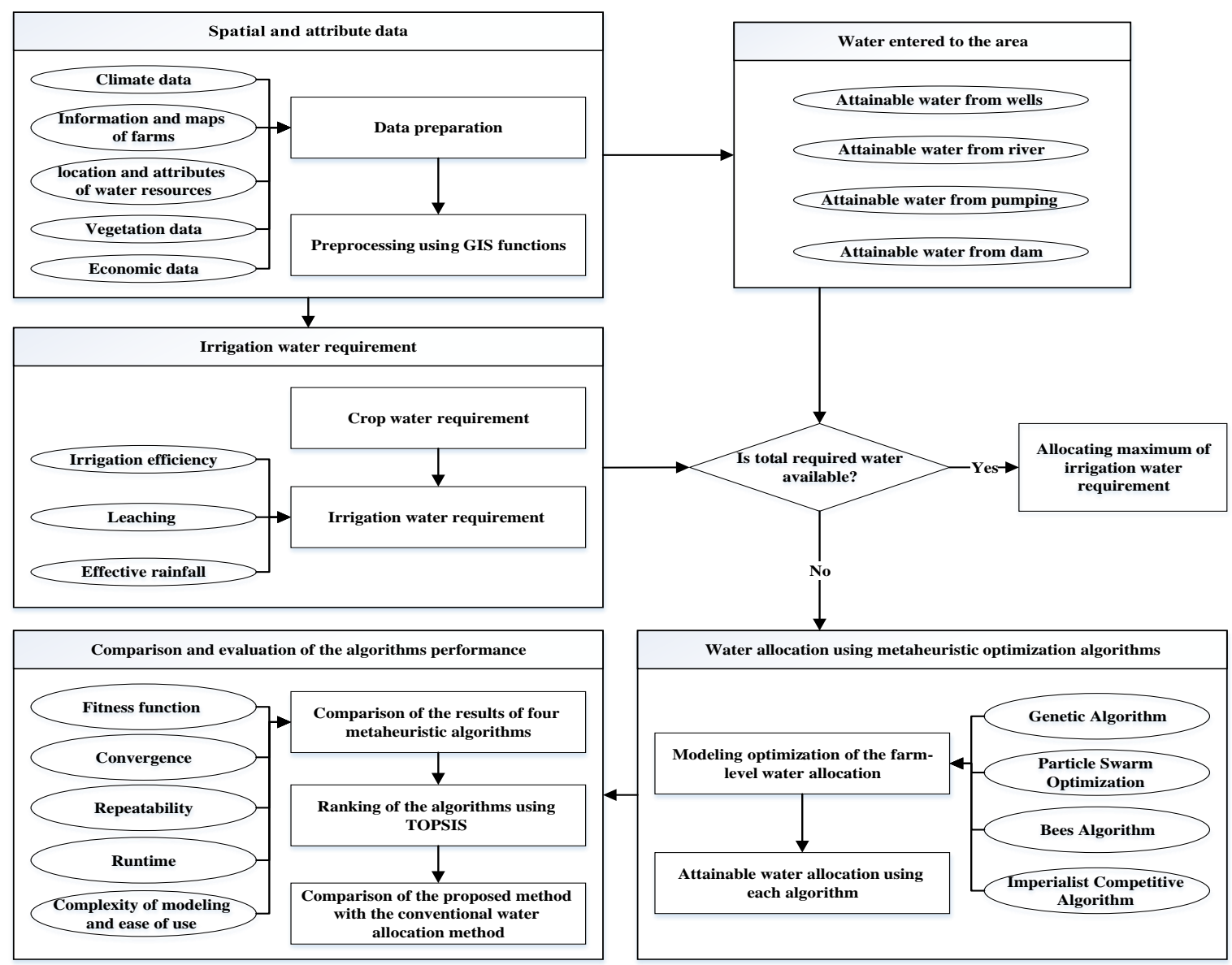

Figure 1. General flowchart of the research.

Following the instructions of the Food and Agriculture Organization (FAO) [5,7,47-49], the crop water requirement is calculated using Equation (1).

$$
E T_{\text {crop }}=K_{c} \times E T_{0}
$$

Here, $E T_{\text {crop }}$ is the crop evapotranspiration (in $\mathrm{mm}$ ), $E T_{0}$ is the potential evapotranspiration of the reference crop (in $\mathrm{mm}$ ), and $K_{c}$ is the crop coefficient. The potential evapotranspiration is the maximum amount of water that can be evaporated by soil and crop. The irrigation water requirement is a part of the crop water requirement that should be covered by irrigation. A part of the crop water requirement is obtained from rainfall, and another portion is used to remove soil salinity. According to Alizadeh and Kamali [50], the maximum irrigation water requirement for any crop can be estimated using Equation (2).

$$
W_{p}=\left(\frac{E T_{\text {crop }}-P_{e}+L}{E_{i} / 100}\right) \times 10,
$$

where $W_{p}$ is the maximum of irrigation water requirement $\left(\mathrm{m}^{3} /\right.$ hectare), $P_{e}$ is the effective rainfall $(\mathrm{mm})$, $L$ is the leaching water (mm), and $E_{i}$ is the irrigation efficiency (percent). In this study, to calculate the maximum of irrigation water requirement, the effective rainfall is regarded as a constant fraction of the rainfall (i.e., 0.75 of the rainfall), leaching is set to $5 \%$, and irrigation efficiency is set to $40 \%$.

In this study, a month is assumed to be the irrigation planning period. The water deficiency in a month is the difference between the total required water and total attainable water from all resources. Equation (3) is used to calculate the total water deficiency $\left(D_{\text {total }}\right)$, where $W_{m i}$ is the irrigation water 
requirement of the $i$ th farm and $Q_{j}$ is the water attainable from resource $j$. In this study, values of all variable related to water are in a cubic meter $\left(\mathrm{m}^{3}\right)$.

$$
D_{\text {total }}=\sum_{i=1}^{n} W_{m i}-\sum_{j=1}^{m} Q_{j}
$$

In this study, to reduce the model complexity, instead of allocating the water itself, the amount of water deficiency is divided between the farms. In other words, the amount of water that should be saved in each farm is determined. Then, by subtracting this amount from the irrigation water requirement, we calculate the water allocated to each farm. Figure 2 represents a solution to the AW problem in which $L_{a i}$ is the amount of water reduced from the irrigation water of farm $i$.

\begin{tabular}{|l|l|l|l|l|l|}
\hline La1 & La2 & La3 & La4 & $\cdots$ & Lan \\
\hline
\end{tabular}

Figure 2. A solution to the allocation of water (AW) problem.

As mentioned, the water allocated to each farm $W_{a i}$ is calculated by Equation (4).

$$
W_{a i}=W_{m i}-L_{a i}
$$

Any solution in the proposed optimisation model should satisfy two constraints:

1. First constraint: The sum of water savings from all farms should not be less than the total water deficiency (Equation (5)).

$$
\sum_{i=1}^{n} L_{a i} \geq D_{t o t a l}
$$

2. Second constraint: The water saving from each farm should be a positive value smaller than its irrigation water requirement (Equation (6)).

$$
0 \leq L_{a i} \leq W_{m i}
$$

As represented by Equation (7), the objective function (fitness) of the allocation optimisation, which is to be maximised, is the total income of the farms.

$$
\operatorname{maximise}\left[\sum_{i=1}^{n}\left(B_{i}\left(\frac{Y_{a}}{Y_{p}}\right)_{i}-C_{i}\right) A_{i}\right]
$$

In this equation, $A_{i}$ is the area of the $i$ th farm (in hectares); $B_{i}$ and $C_{i}$ are the income and cost related to the $i$ th farm (in Rials per ha); $Y_{a}$ and $Y_{p}$ are the actual and potential yields (in kg per ha) related to the deficit irrigation and complete irrigation conditions, respectively. In fact, $Y_{a} \Upsilon_{p}$ represents the efficiency of the crop, which is a function of the crop production proportional to the received water (water production function). Water production functions are used to calculate the crop production of a time period, considering parameters such as the provided water, evaporation, and transpiration. In this study, the efficiency of the crop is calculated using Equation (8), which is a well-known water production function $[9,23,49,51-54]$.

$$
\frac{Y_{a}}{Y_{p}}=\prod_{j=1}^{n}\left[1-K_{y j}\left[1-\frac{W_{a}}{W_{p}}\right]\right]
$$


Here, $j$ is the crop growth stage, $n$ is the number of crop growth stages, $K_{y j}$ is the response factor of yield $y$ to the water (yield response factor) in stage $j, W_{p}$ is the irrigation water requirement that is already defined for each crop and growth stage, and $W_{a}$ is the water allocated through optimisation.

In Equation (8), if the crop irrigation equals the full irrigation $\left(W_{a}=W_{p}\right)$, then $\left(Y_{a} Y_{p}\right)=1$. If the crop irrigation is less than the full irrigation $\left(W_{a}<W_{p}\right)$, then $\left(Y_{a} Y_{p}\right)<1$ and its value changes linearly according to $W_{a} / W_{p}$ (with a slope proportional to $K_{y}$ ). As mentioned, in relation to Equation (8), $K_{y j}$ is the response factor of yield $y$ to the water in the growth stage $j$. If the coefficient is greater than 1 , then the yield of the product is highly sensitive to deficit irrigation; if this coefficient is less than 1 , then the product is resistant to water shortage; and if this coefficient is 1 , then the rate of yield reduction is directly proportional to the amount of water reduction [49].

To calculate the objective function of each solution in the optimisation, the water allocated to each farm should be calculated using Equation (4). Then, the water production function $\left(Y_{p} \Upsilon_{a}\right)$ and objective function are calculated using Equations (7) and (8), respectively. In the following sections, the formulation of the problem in the context of each algorithm is described.

\subsubsection{Modelling GA Operators in AW Problem}

The genetic algorithm is inspired by Darwin's evolution theory. In nature, through natural selection, crossover, and rare mutations of chromosomes, the generations are evolved gradually [55]. Here, the modelling of GA operators for the AW problem is described. In the genetic algorithm, each solution is a chromosome. As a result, the chromosome shown in Figure 2 is a solution to the AW problem, and each gene of the chromosome is the water deficit allocated to a particular land. After generating the initial population by creating a series of random chromosomes, the roulette wheel method is used to select the parent for the crossover. In this study, the one-point crossover method is used. Figure 3 shows an example of a crossover in AW. For simplicity, in the following figures, the number of genes in the chromosome is shown as six, which is much less than the number of farms in the real chromosome.

\begin{tabular}{|l|l|l|l|l|l|l|}
\hline 2010.4 & 3070.1 & 550.1 & 900.8 & 2170.5 & 1700.1 & First Parent \\
\hline 800.1 & 2008.9 & 3542.2 & 570.4 & 1850.6 & 2600.3 & Second Parent \\
\cline { 1 - 5 } 2010.4 & 3070.1 & 550.1 & 570.4 & 1850.6 & 2600.3 & Child \\
\hline
\end{tabular}

Figure 3. An example of crossover in AW problem.

The result of a crossover might be an incorrect chromosome. In a chromosome resulting from such a crossover, every gene has already been a gene of one of its parents. Therefore, the second constraint, described by Equation (6), is already satisfied. If the sum of gene values is less than the total water deficiency, then the difference should be added to the gene values, to comply with the first constraint, as described by Equation (5). To do so, $10 \mathrm{~m}^{3}$ is added to the value of a randomly selected gene. Obviously, the second constraint should be checked for such edited genes. The editing of the randomly chosen genes is continued until the first constraint is also satisfied. As the modifications are slight, the resulting chromosome can still be considered as the result of a crossover between the two parents.

For any chromosome, a random value is created between 0 and 1 . If this value is less than that of the mutation rate, then the chromosome is mutated. To do so, $50 \mathrm{~m}^{3}$ is subtracted from a randomly selected gene and added to another randomly selected gene, such that the second constraint is not violated. This action is repeated $k$ times. Figure 4 shows a mutation when $k=1$. Finally, for elitism, only $15 \%$ of the chromosomes with the best fitness values (called elites) are accepted to be present in the next generation. Here, the number of elites is set to 15 by trial and error. 


\begin{tabular}{|l|l|l|l|l|l|l|}
\hline 2010.4 & 3070.1 & 550.1 & 900.8 & 2170.5 & 1700.1 & Original Chromosome \\
Mutated Chromosome
\end{tabular}

Figure 4. An example of mutation in AW problem.

\subsubsection{Modelling BA Operators in AW Problem}

The bees algorithm was introduced by Pham et al. [56]. In this algorithm, the integration of a stochastic search with a local search is used to find the optimum solutions. At the beginning of the algorithm, a certain number of random problem solutions (scout bees) are created as the initial populations. Then, the quality of the solutions is calculated using the objective function, and a certain number of the best bees are selected as employed bees. The vicinity of each employed bee is searched by some follower (onlooker) bees. The neighbourhood of the better employed bees (elites) are searched by more follower bees. The employed bee is replaced by any of its followers if the follower is better than it. The collection of such improved employed bees along with some new scout bees make the next generation of bees. The best solution of each generation is stored, and the process is repeated until the stop condition is satisfied [57,58]. In the following, the modelling of algorithm operators/stages for the AW problem is described.

Any solution to the AW problem, as shown in Figure 2, that satisfies the constraints is regarded as a bee in the BA. A group of 30 such solutions is created as scout bees, to be the first population of bees $(n=30)$. For all bees, the objective function (fitness) value is calculated according to Equation (7). From the 30 bees, 20 with the highest fitness are selected as the employed bees $(m=20)$. Again, from these, the 10 best ones are selected as elite bees $(e=10)$. Respectively, 4 and 2 follower bees are allocated to each elite bee and each non-elite employed bee (nep $=4$ and $n s p=2$ ).

The neighbourhood searches around the employed bees is done by the creation of follower bees. Each follower bee is a copy of the original bee that is slightly changed in a manner that is highly similar to the mutation process of GA. Both the water transformed between genes and the number of changed genes in the neighbourhood search are less than those of the GA mutation. The reason is that the goal of GA mutation is the search of unexplored areas, whereas the goal of neighbourhood search is to generate very similar yet different solutions to the original bee.

In any iteration, the general number of bees should be $n$, and $m$ bees are generated in the previous stage. Then, $s=n-m$ scout bees are needed to explore the new search-space areas. Each scout bee is generated by random allocation of the water savings to the farms while obeying the defined constraints.

\subsubsection{Modelling PSO Operators in AW Problem}

The PSO algorithm was first introduced by Eberhart and Kennedy [59], who were inspired by the studies of Heppner and Grenander [60] on bird swarms. The main element of the algorithm is the particle. The location of the particle in the search space is a solution to the problem. Each particle has a memory of its previous locations and moves in the search space towards better solutions by changing its components (solution parts). Its movement, in any iteration, is a combination of its last move, move towards its best personal location, and move towards the best previous location of the particle's group. Like similar algorithms, any location of a particle is evaluated by an objective function [61-63]. In PSO, a movement (a change in the location) of a particle is called velocity. As shown in Equation (9), the new location of a particle is calculated by adding its velocity to its last location [63].

$$
\vec{x}_{i}=\vec{x}_{i}+\vec{v}_{i}
$$

Any location of each particle or solution to the problem is a vector of water savings defined for the farms (Figure 2). Each velocity is a vector of the changes that are to be made in the amount of water savings of the farms. These are shown in Figure 5. 


\begin{tabular}{|l|l|l|l|l|l|l|}
\hline 2010.4 & 3070.1 & 550.1 & 900.8 & 2170.5 & 1700.1 & Last particle location \\
\cline { 1 - 5 } 32.1 & -11.6 & -20.5 & 9.2 & 40.4 & 1.0 & Velocity \\
\cline { 1 - 4 } 2042.5 & 3058.5 & 529.6 & 910.0 & 2210.9 & 1701.1 & New particle location \\
\cline { 1 - 4 } & & & & & &
\end{tabular}

Figure 5. An example of the new location of a particle (a water-saving allocation) after a movement.

For any new location, the constraints should be checked. With regard to the second constraint, if the water-saving of a farm (i.e., the water to be saved in that farm) is less than zero or more than the irrigation water requirement, then the solution is incorrect and should be returned to the solution space. When it is less than zero, it will be set to zero and when it is more than the irrigation water requirement, it will be set to the irrigation water requirement. Thereafter, the first constraints should be checked. If the sum of the water savings of all farms is less than the total water deficiency, then the new location of the particle is not correct. To repair it, we randomly select one of the farms and add 10 cubic meters to its water saving value. Again, if this condition results in disobedience of the second rule, then the change is not exerted, and a different farm is selected for the change. This process is repeated until the first constraint is satisfied.

The particle velocity is updated using Equation (10) [63].

$$
\vec{v}_{i}=w \vec{v}_{i}+c_{1} \vec{\varphi}_{1 i}\left(\vec{p}_{i}-\vec{x}_{i}\right)+c_{2} \vec{\varphi}_{2 i}\left(\vec{p}_{g}-\vec{x}_{i}\right)
$$

In this equation, $x_{i}$ is the previous location; $p_{i}$ and $p_{g}$ are the personal and global best locations; $c_{1}$ and $c_{2}$ are constants showing the relative importance of $p_{i}$ and $p_{g} ; \Phi_{1}$ and $\Phi_{2}$ are the weights that are defined randomly in each iteration of the algorithm; and $w$ is the inertia weight that controls the effect of the previous velocity on the present velocity [64].

In the first iteration, the present location of each particle is regarded as its best location $p_{i}$. In the next iterations, if the present location is better than $p_{i}$, then it replaces $p_{i}$. In any iteration, the $p_{i}$ locations of all particles are compared and their best one is taken as $p_{g}$.

\subsubsection{Modelling ICA Operators in AW Problem}

In the ICA algorithm, a population of solutions (called countries) is created randomly. Some of the best countries (according to their fitness values) are selected as imperialists, and the remainder of the population are the colonies of those imperialists. More powerful imperialists, depending on their power, have more colonies. With the formation of primitive empires, imperialistic competition begins between them. Weaker empires usually fail in the competition, lose their power, and are gradually eliminated. Therefore, during the imperialistic competition, the power of the great empires is gradually increased and the weaker empires are eliminated [65,66]. In the following, the modelling of ICA operators for the AW problem is explained.

Each country is a solution to the AW problem, as shown in Figure 2. Among $N_{\text {country }}=100$ initial solutions (countries), $N_{i m p}=10$ solutions with better fitness values are selected as imperialists and other countries are regarded as colonies. In the continuation, the colonies must be assimilated into the imperialists. This assimilation is in accordance with the imperialists' fitness values. The greater the fitness values, the more likely it is to capture the colonies. For this purpose, the roulette wheel is used. In this study, Equation (11) is used to calculate the assimilation policy.

$$
X^{\prime}=X+\beta \times r \times d
$$

In Equation (11), $X^{\prime}$ and $X$ are the new and old locations (assimilation) of the colony, $d$ is the distance of the imperialist from its colony, and $r$ is a random vector. $\beta$ is a constant coefficient that 
determines how close a colonial country gets to the imperialist. In the vector $r$, for any variable (dimension) of the country, a random number in the range of $[0, Q]$ is created. This results in an imprecise movement of the colony towards the imperialist [65]. Figure 6 shows an example of colonization (assimilation) of a colony by an imperialist in AW problem, when $\beta$ equals to 2 and $Q$ equal to 0.5 .

\begin{tabular}{|c|c|c|c|c|c|c|}
\hline 2010.4 & 3070.1 & 550.1 & 900.8 & 2170.5 & 1700.1 & Imperialist location \\
\hline 800.0 & 2008.3 & 3542.5 & 570.3 & 1850.9 & 2600.7 & Initial location of the colony \\
\hline 0.01 & 0.38 & 0.17 & 0.20 & 0.45 & 0.12 & r vector \\
\hline 824.2 & 2815.3 & 2525.1 & 702.5 & 2138.5 & 2384.7 & Final location of the colony \\
\hline
\end{tabular}

Figure 6. An example of a colony assimilated into an imperialist in the AW problem.

For the new colony's position, we must examine the AW constraints so that the correct solution is made. The process is exactly the same as checking the constraints in the PSO algorithm after changing the position of particles. If the colony's new position is not in the problem space, then the process of position modification is also similar to the correction of the particle's position in PSO.

As colonies move towards the imperialist, a colony may have a higher fitness function than the imperialist. In this case, the imperialist is replaced by its stronger colony and the algorithm continues with a new imperialist [65]. The total power of each empire is calculated using Equation (12) [65].

$$
\text { T.C. } . n=f\left(\text { imperialist }_{n}\right)+\xi \operatorname{mean}\left\{f\left(\text { colonies of empire }_{n}\right)\right\}
$$

In this equation, T.C. $n$ is the power of the $n$th empire, f imperialist $\left._{n}\right)$ is the imperialist's fitness, $\xi$ is a positive number between 0 and 1 , and mean $\{$ (colonies of empiren) $\}$ is the average fitness of the colonies of the empire $n$. Consideration of small values for $\xi$ causes the power of an entire empire to be nearly equal to the power of its central government (imperialist). By contrast, large values of $\xi$ lead to an increase in the effect of the empire's colonies on the determination of its total power [66].

Any empire that cannot increase its strength and lose its power is gradually eliminated during imperialistic competition. In other words, over time, weak empires lose their colonies and stronger empires capture these colonies and increase their power [66]. From the colonies of the weakest empire, $\mathrm{N}$ weakest colonies are selected and given to other empires. The more powerful an empire is, the more probably it obtains these colonies. In this study, the roulette wheel method is used to select the empire that captures the colony. In this study, whenever an empire loses all of its colonies, its imperialist is changed into a colony and is assimilated into one of the other empires (selected using the roulette wheel method). In other words, that empire is deleted.

The optimal values of the algorithms' parameters are determined by trial and error based on repetitive executions of the algorithms. The use of the trial-and-error method to obtain the value of the optimisation algorithm parameters is explained in [67].

\subsubsection{Comparison Criteria}

Five criteria, namely, fitness function, convergence, repeatability (robustness), runtime, and modelling complexity, are used to evaluate and compare the algorithms. In addition, the algorithms are prioritised for AW using the TOPSIS method. Finally, the result of the best algorithm is compared with the currently used method of AW in the area. In the following, the mentioned criteria are explained. 
- Fitness function

The fitness function is the total profit of all land units resulting from the water deficit allocation performed by each algorithm.

- Convergence of algorithms

The speed/trend of an algorithm in finding better values of fitness-function is called convergence speed/trend and is assumed to be one of the superiority measures of an algorithm. In this study, the constancy of the fitness value is considered as the stop condition of the algorithms. This concept is used in two ways. The first is when, after many iterations, the algorithm still continues to find better solutions but with a very low convergence rate. In such cases, sufficient convergence is assumed to be achieved and the algorithm can be terminated. The second is when the fitness value does not improve for a specified large number of iterations (e.g., 200). Then, we assume that a solution close enough to the optimum is found, and the algorithm is terminated.

- Repeatability test

A more repeatable (robust) algorithm achieves more similar results in separate executions. To evaluate this criterion, each algorithm is executed 10 times, and the variance of best benefit values found by each algorithm in 10 runs is calculated. In addition to the variance of the objective function, the variance of the solutions (i.e., the water allocated to each land) could also be used to evaluate the repeatability of an algorithm. This condition means checking the variations in the water allocated to each land in 10 different runs of the algorithm. Both variance concepts are considered in this study. In fact, to have a better comparison, the variance of the normalised values is used. The values are normalised using Equation (13). Owing to the normalisation of the data, any variance value is between 0 and 1 . When the variance is closer to 0 , the algorithm is more stable.

$$
N_{i j}=\frac{S_{i j}-\min \left(S_{i j}\right)}{\max \left(S_{i j}\right)-\min \left(S_{i j}\right)} .
$$

- Runtime

To test the speed and runtime of the algorithms, two different stopping criteria are used. In the first one, the algorithms continue to run until they reach a specified fitness-function value. Then, their runtimes are compared. In other words, the algorithm runtimes (in seconds) are studied while reaching a specified fitness-function value is considered as the stopping condition. In the second, the algorithms are run for a specified time period and the best fitness-function values found by them, in that specified time, are compared.

- Modelling complexity and ease of use

As mentioned, any meta-heuristic algorithm has certain parameters that must be calibrated first. In this study, this task is conducted using the trial-and-error method. Therefore, from the user's point of view, calibrating an algorithm with fewer parameters is easy. As a result, the number of algorithm parameters can be considered as another measure of comparison. Another comparison parameter considered is the number of algorithm operators. These operators should be defined for the special circumstance of the optimisation problem. In fact, the fewer operators it has, the easier the modelling of the optimisation problem is.

\section{- TOPSIS}

In this study, the TOPSIS method is used to rank the algorithms' performance on the AW problem, considering the aforementioned criteria. In the TOPSIS method, $\mathrm{m}$ choices are evaluated by $\mathrm{n}$ criteria. 
Therefore, the solution space can be considered as an n-dimensional coordinate system (space), in which $\mathrm{m}$ points (solutions) exist. In this technique, each solution is ranked based on its distance to both the ideal positive $(A+)$ and ideal negative $(A-)$ solutions. The $A+$ is a solution that has the largest values for the positive criteria and the lowest values for the negative criteria. Obviously, $A$ - solution is the opposite of $A+$. The TOPSIS method includes the following steps [68]:

1. Creating a decision matrix;

2. Calculating the normalised decision matrix;

3. Calculating the normalised weighted decision matrix;

4. Determining the positive and negative ideal solutions;

5. Calculating the distances using the Euclidean norm;

6. Calculating the relative closeness index to the ideal solutions;

7. Ranking of the solutions.

In this study, the aforementioned comparison criteria are the inputs to TOPSIS, used to calculate the decision matrix. Among them, the objective function is the only positive criterion. The negative criteria are the run-time, repeatability measures of variance, and number of modelling parameters. After the above steps are performed, for each algorithm, the relative closeness index $(C L)$ is calculated. Algorithms are ranked according to $C L$ values.

- Comparing the best meta-heuristic algorithm with AW method currently used in the area

In general, it is useful to compare the results of the best algorithm with those of the typical method of area-based AW. Although in developed countries better AW models are typically used, in the present condition of the study area, the irrigation water is often allocated merely based on land area. First, the total amount of available water is allocated according to the land area (Equation (14)). Of course, the already harvested and uncultivated lands are excluded in the calculations. Then, the crop efficiency $(Y a / Y p)$ values and total income of the lands are calculated using Equations (8) and (7), respectively.

$$
W_{a i}=\frac{A_{i} \times \sum_{j=1}^{m} Q_{j}}{\sum_{i=1}^{n} A_{i}}
$$

Here, $W_{a i}$ is the water allocated to farm $i, A_{i}$ is the area of the farm $I$, and $Q_{j}$ is the water attainable from source $j$.

\subsection{Materials}

In this section, the study area, the data used, and the data processing steps are discussed.

\subsubsection{Study Area}

In this study, a part of the agricultural lands in Darram village located in Tarom County in Zanjan province was selected as the study area (Figure 7). The irrigation water resources in this region are Mirza Khanlu Dam, Ghezel-Ozan River, and wells drilled in the area. Over the last few years, the main problem facing agriculture in this area has been the shortage of irrigation water, especially in early and mid-summer. This condition resulted in the dryness and decline of agricultural products in most of the lands. 


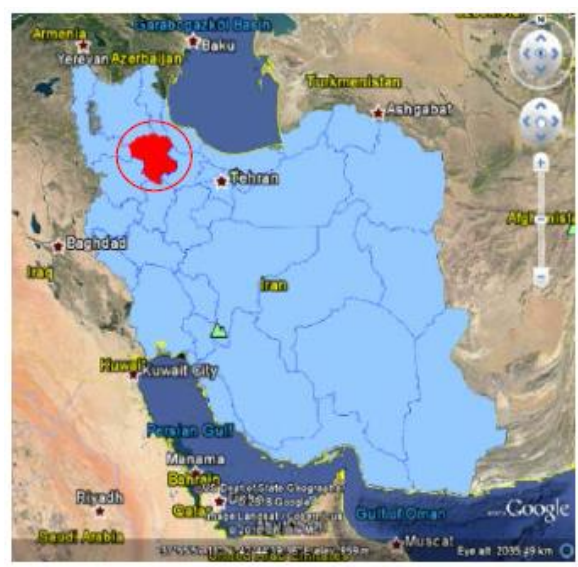

(a)

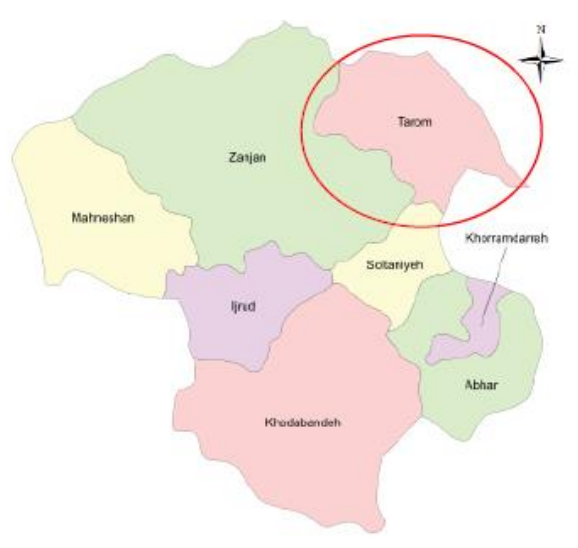

(b)

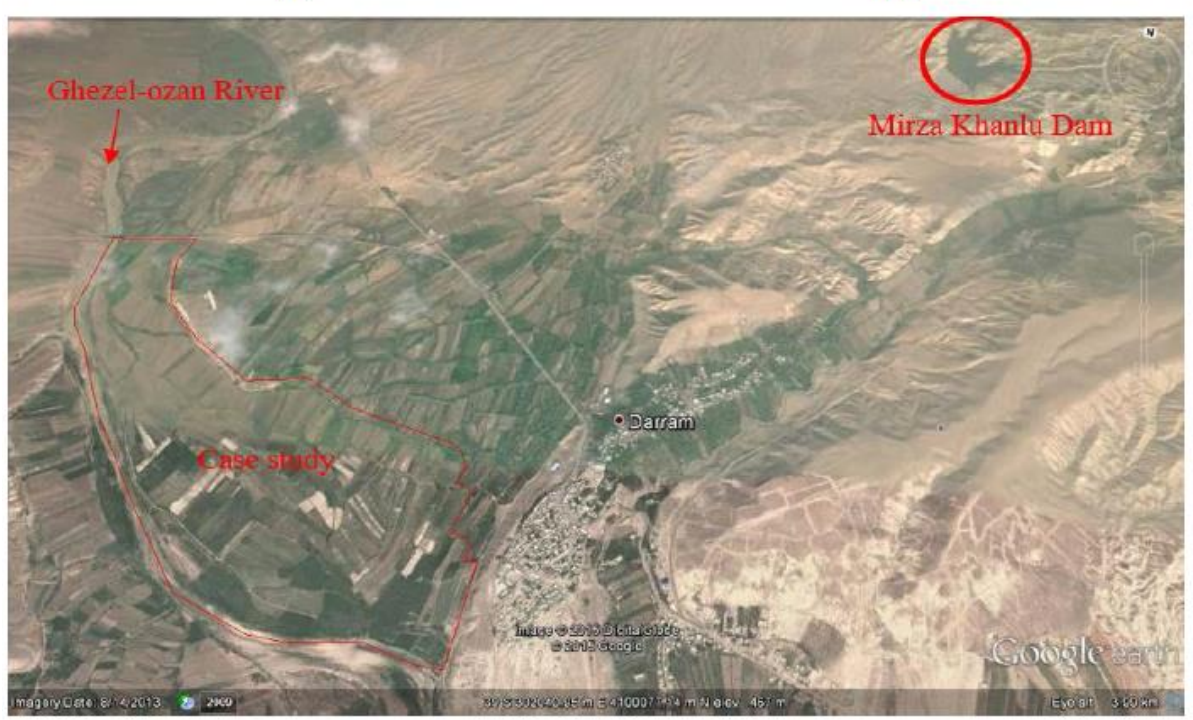

(c)

Figure 7. (a) Location of Zanjan province in Iran; (b) location of Tarom county in Zanjan province; (c) location of Darram village, study area, Mirza Khanlu Dam, and Ghezel-Ozan River. 


\subsubsection{Research Data Set}

In the following, the research data are sorted and discussed.

Climate data: The data include temperature, humidity, rainfall, and others obtained from the data available on the OPTIWAT software and database (Iran Air and Climatology Comprehensive Web Site [69]).

Information and maps of agricultural lands in the region: This dataset includes the maps of farms in the study area, irrigation network map, the present crops of each farm, and their planting dates. The attempts of the researchers to collect the required maps from organisations such as the Agricultural Office of Tarom, Zanjan Regional Water, Water and Sewage Office of Zanjan, Natural Resources Office of Zanjan, and Natural Resources Office of Tarom was not successful. Therefore, the needed maps were generated using downloaded Google Earth satellite images and the data collected by direct field surveys in the area. The data related to the present crops of each land and their planting dates were collected by field visits and interviews with farmers of the region for the cultivation year of 2014-2015. Then, they were added to the attribute data of the lands. Considering the research objectives, the accuracy of the generated maps was acceptable.

According to the field visit, the farmers experienced drought in the year of collecting the research dataset. As stated by the farmers, the common summer rains usually cause a seasonal flood in the Ghezel-Ozan riverbed. In such cases, with the temporal rise of river water, the farms' water needs could be satisfied for a few weeks. However, such seasonal rains did not happen that year. Therefore, that agriculture year was selected for the present study.

Location and attributes of water resources: As mentioned, water resources of the study area are the Mirza Khanlu Dam, the wells of the region, and the Ghezel-Ozan River. Two canals from two different sides transfer part of the river's water to the area for irrigation. In addition, water is pumped from the same river to irrigate some lands along the river. The location of the wells and pumping sites are collected by fieldwork. In this study, water resources, water canals, and agricultural lands are represented as points, lines, and polygons, respectively. The location of the dam and river are extracted from Google Earth. The attainable volume and attributes of water resources in different periods of the year are collected from the Study Phase Reports on Mirza Khanlu Dam [70] and field observations.

Vegetation data: Crop information, including the growth period, crop coefficients for the four stages of crop growth (initial stage, development, midseason, and late season), yield response factor, and so on are determined for the arable crops in the area. These are concluded using the FAO journals, previous research results [5,49,71,72], official reports for those crops [73], and OPTIWAT databases.

The values of $K_{y j}$ (used in Equation (8)) for 33 crops are given in the instruction number 33 of FAO and are used and evaluated in many studies [51,71]. Those values are used in the present research (Table 1). For the crops not covered in that instruction, the values proposed by other instructions and studies $[5,49,71,72]$ are used.

Crop coefficient factor has an important role in determining the water requirement of plants. It is affected not only by the plant type and growth stage, but also by the climatic conditions and soil surface evaporation [50]. The crop coefficients are presented in the FAO guidelines [47,48]. Ideally, these coefficients should be precisely determined through research and fieldwork for any region. However, because of the limitations of this study, the same values provided by FAO [47] are accepted and used here (Table 2). 
Table 1. Values of $K_{y}$ for region crops according to Food and Agriculture Organization (FAO) Guideline No. $33[5,49,71,72]$.

\begin{tabular}{ccccc}
\hline \multicolumn{2}{c}{ Crop Yield Response Factor to Water Deficit at Each } & Growth Stage & \multirow{2}{*}{ Crop } \\
\cline { 1 - 3 } Tr-1110 & Tr-1101 & Tr-1011 & Tr-0111 & \\
\cline { 1 - 3 } $0.25^{1}$ & 0.55 & 0.65 & 0.20 & Wheat \\
0.40 & 0.50 & 0.60 & 0.20 & Barley \\
0.20 & 0.75 & 1.10 & 0.20 & Vicia faba \\
0.30 & 0.80 & $1^{2}$ & 0.45 & Onion \\
0.20 & 0.70 & $1^{2}$ & 0.60 & Potato \\
0.20 & 0.70 & 0.90 & 0.20 & Pea \\
0.40 & 0.80 & 1.10 & 0.40 & Tomato \\
0.50 & 1.33 & 1.10 & 1 & Rice \\
0.30 & 0.80 & 0.80 & 0.70 & Cantaloupe \\
0.30 & 0.80 & 1 & 0.45 & Garlic \\
\hline
\end{tabular}

Tr-0111: Deficit irrigation has occurred at the initial stage. Tr-1011: Deficit irrigation has occurred at the development stage. Tr-1101: Deficit irrigation has occurred at the middle stage. Tr-1110: Deficit irrigation has occurred at the final stage. ${ }^{1}$ These values could not be found in the FAO Guideline No. 33. Therefore, for these values, the IAEA information [5,49] was used. ${ }^{2}$ These values could not be found in the FAO Guideline No. 33. Therefore, the reference data [23] was used for these values. ${ }^{3}$ These values could not be found in the FAO Guideline No. 33 . Therefore, the reference data [74] were used for these values.

Table 2. Crop coefficient $\left(K_{c}\right)$ for crops at different stages [47].

\begin{tabular}{cccc}
\hline & Crop Coefficient $\left(\mathbf{K}_{\mathbf{c}}\right)$ & & Crop \\
\cline { 1 - 3 } Late Season & Midseason & Initial Crop Stage & \\
\hline 0.25 & 1.15 & 0.4 & Wheat \\
0.25 & 1.15 & $0.30^{1}$ & Barley \\
0.3 & 1.15 & 0.5 & Vicia faba \\
0.75 & 1.05 & $0.70^{1}$ & Onion \\
0.75 & 1.15 & $0.50^{1}$ & Potato \\
1.10 & 1.15 & 0.5 & Pea \\
0.70 & 1.15 & $0.60^{1}$ & Tomato \\
0.70 & 1.20 & 1.05 & Rice \\
0.60 & 0.85 & 0.5 & Cantaloupe \\
0.70 & 1 & $0.70^{1}$ & Garlic
\end{tabular}

${ }^{1}$ In paper 56 of $\mathrm{FAO}$, an approximate value is presented for several crops in each group. This is assumed to represent the crop coefficient factor of the crop group under the standard water management conditions [47].

To determine the $K_{c}$ for each land's crop during the irrigation period, the planting time and length of different growth stages of the crop should be considered. In other words, the length of different growth stages of the crop (initial, midseason, and late season) should be added to the planting date until the considered water-allocation time. This condition determines the growth stage of the crop at the considered water-allocation time. The planting dates of land crops are determined by interviewing the farmers. Furthermore, in the study area, the lengths of crops' growth stages were extracted from the reports of Zanjan Agriculture Organization and OPTIWAT software database.

Economic Information: The costs and incomes of the region's crops were determined for one year using the reports of the Agriculture Organization and interviews with the farmers.

Table 3 provides general characteristics of agricultural lands, meteorological parameters, as well as crops specifications in the study area. 
Table 3. General characteristics of agricultural lands, climate, and crops in the study area for the cultivation year of $2014-2015$.

\begin{tabular}{|c|c|c|c|c|c|c|c|c|c|}
\hline \multicolumn{2}{|c|}{ Information About the Study Area ${ }^{2}$} & \multicolumn{2}{|c|}{$\begin{array}{l}\text { Meteorological Parameters in the Study Area } \\
\text { (Annual Average Value) }\end{array}$} & \multicolumn{6}{|c|}{ Crop Specifications in the Study Area } \\
\hline Value & Parameter & Value & Parameter & $\begin{array}{l}\text { Income of Crop }{ }^{2} \\
\text { (Rials per ha) }\end{array}$ & $\begin{array}{l}\text { Cost of Crop }{ }^{2} \\
\text { (Rials per ha) }\end{array}$ & $\begin{array}{l}\text { Irrigation } \\
\text { Method }^{2}\end{array}$ & $\begin{array}{l}\text { Maximum Root } \\
\text { Depth }^{1}(\mathrm{~cm})\end{array}$ & $\begin{array}{l}\text { Maximum Crop } \\
\text { Height }^{1}(\mathrm{~cm})\end{array}$ & Crop \\
\hline Loam & Soil & 75 & Maximum relative humidity (\%) & $53,000,000$ & $43,500,000$ & Furrow & 100 & 100 & Wheat \\
\hline Subtropical climate & Climatic & 42 & Minimum relative humidity (\%) & $29,000,000$ & $23,200,000$ & Furrow & 100 & 100 & Barley \\
\hline \multirow[t]{8}{*}{ Ghezel- Ozan- Sefid-rood } & Catchment area & 59 & Relative humidity (\%) & $80,000,000$ & $50,000,000$ & Furrow & 60 & 80 & Vicia faba \\
\hline & & 23.3 & Maximum temperature $\left({ }^{\circ} \mathrm{C}\right)$ & $141,300,000$ & $113,000,000$ & Furrow & 45 & 50 & Onion \\
\hline & & 11.9 & Minimum temperature $\left({ }^{\circ} \mathrm{C}\right)$ & $243,800,000$ & $195,000,000$ & Furrow & 50 & 60 & Potato \\
\hline & & 17.6 & Temperature $\left({ }^{\circ} \mathrm{C}\right)$ & $60,000,000$ & $30,000,000$ & Furrow & 65 & 50 & Pea \\
\hline & & 247 & Rainfall (millimeter) & $200,000,000$ & $120,000,000$ & Furrow & 100 & 60 & Tomato \\
\hline & & 2781 & Sunshine (hour) & $250,000,000$ & $150,000,000$ & Basin & 75 & 100 & Rice \\
\hline & & 1366 & Evaporation (millimeter) & $100,000,000$ & $40,000,000$ & Furrow & 90 & 40 & Cantaloupe \\
\hline & & & & $250,000,000$ & $170,000,000$ & Furrow & 40 & 40 & Garlic \\
\hline
\end{tabular}

${ }^{1}$ Extract from the OPTIWAT software database for the study area. ${ }^{2}$ Based on reports of Zanjan Agricultural Office and interviews with farmers. ${ }^{3}$ Based on meteorological office reports. 


\subsubsection{Data Preparation}

At this stage, after the preparation of spatial data, the collected data including the type and planting date of the crops for each land, the flow of wells and pumps, and others are attributed to spatial features. The study area covers 298 farms with an area of more than 103 ha.

The planting date of crops are classified into time intervals of 10 or 15 days, according to the crop type. For example, the planting dates of the first and second planting-period tomatoes are the first and second 10 days of March, respectively. For potato, they are the first and second 10 days of February. The planting-date variances of less than 10 days have trivial effects on the irrigation rate. Therefore, the planting dates are grouped into four classes (Figure $8 \mathrm{~b}$ ). Two lands with a similar planting period might have different planting dates if they have different crop types. For example, a land with tomato of period 1 is cultivated in the first decade of March, but a land with potato of period 1 is cultivated in the first decade of February.

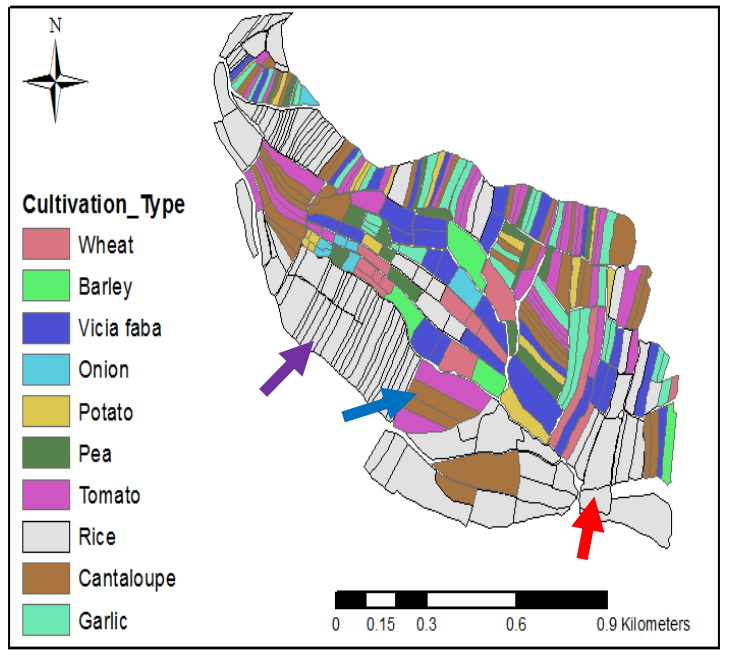

(a)

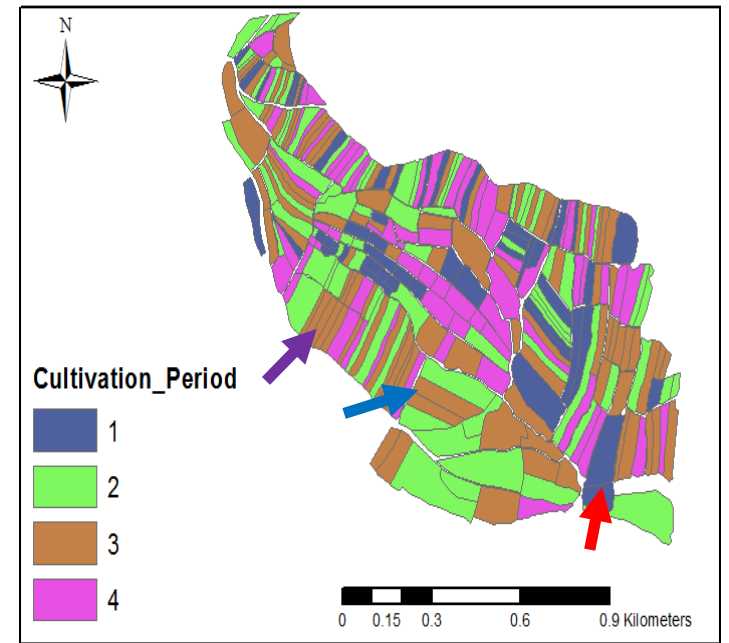

(b)

Figure 8. (a) Crop types of farms; (b) periods of cultivation (planting dates) of farms.

Some adjacent lands have the same crop type and similar planting periods (the arrows of Figure $8 \mathrm{a}, \mathrm{b}$ show examples of these lands). As the AW is based on area, crop type, and growth stage (resulted from planting dates), merging such lands is possible to reduce the computation load. By integrating these lands using GIS functions of ArcGIS software, we obtained 235 land units.

\section{Results}

In this study, ArcGIS 10.2 software was used for data preparation and output visualisation and MATLAB environment was used to implement the meta-heuristic algorithms. To simplify the implementation, the AW model was tested for July only, which was the most critical period in the study area. In addition, when calculating the fitness function, we assumed that in the former and later months, sufficient irrigation was conducted. However, the proposed model can be implemented for other months and periods.

In the proposed method, the input of the model for each month includes the amount of available water in that month, water allocated in the previous months, plant type, growth stage, and some other parameters. The output is the optimal AW to all farms for that month. In the study area, according to the climatic conditions, experiences in previous years, and interviews with farmers, the water shortage problem happens only in July. As a result, the assumption of full irrigation for the months before and after July is in coherence with the actual conditions of the study area. This assumption is made merely for the evaluation of the proposed model and comparison of the algorithms. In using this method for 
other areas with different water availability conditions, the model should be applied month to month, according to the actual amount of irrigation in the previous months.

It should be noted that some lands (56 farms) had already been harvested in July. Therefore, they were not considered in the calculations. According to the calculations, the amount of water required by all lands is 302,420 cubic meters in July. However, only 265,188 cubic meters of water is attainable from all resources. Thus, the water shortage is 37,232 cubic meters (i.e., $12.3 \%$ of the total required amount of water). Therefore, a deficit irrigation strategy should be considered. The allocation of a limited amount of water to 179 land units with different crop types and planting periods, such that the total income is maximised and the total costs are minimised, is not a simple problem. Usually, meta-heuristic methods are applied to solve such complex problems. In the following, the results of AW to all land units by four meta-heuristic algorithms (GA, PSO, BA, and ICA) are presented.

The profit of all lands resulting from each algorithm, considering the deficit irrigation condition, are presented in Table 4. In addition, for the sake of comparison, the maximum profit, obtainable by full irrigation of all land in all months, is also presented. All the results presented in this section, including the contents of Tables 4 and 5 and Figures 9-11, are related to the best execution of each algorithm among its 10 different executions. In fact, to test and compare the runtime and repeatability of the algorithms, for which the results are presented in the next section, each algorithm was executed 10 times. In this section, the results of the best one among the 10 executions of each algorithm are presented as the final solution for each algorithm.

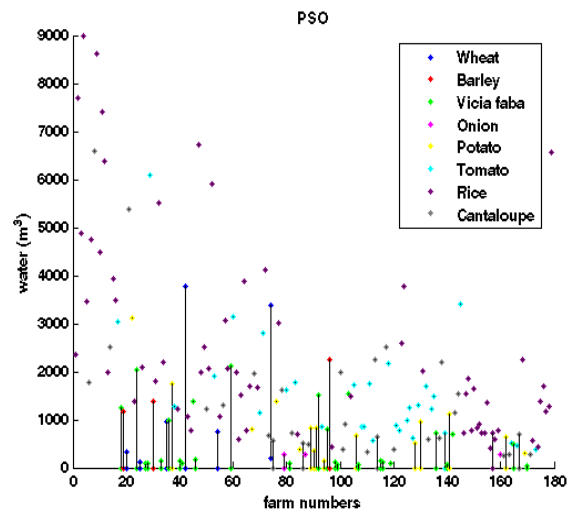

(a)

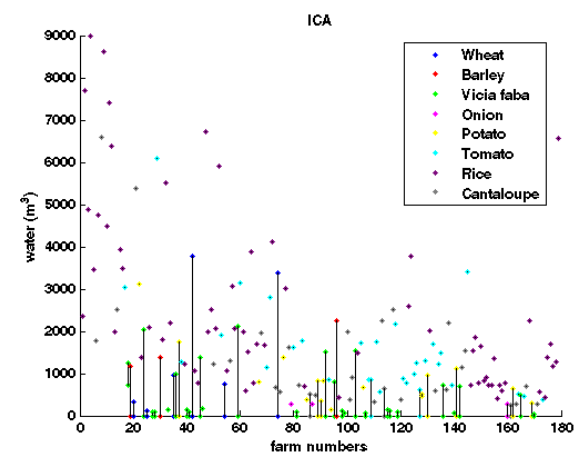

(c)

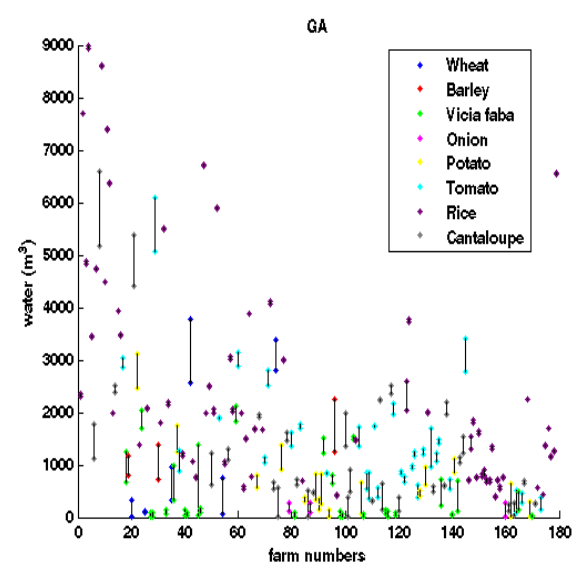

(b)

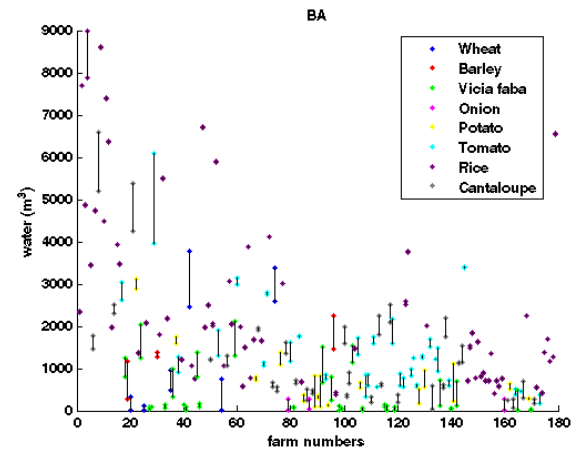

(d)

Figure 9. Comparison of the total irrigation water with deficit irrigation water allocated to each land in July by the algorithms: (a) particle swarm optimisation (PSO), (b) genetic algorithm (GA), (c) imperialist competitive algorithm (ICA), and (d) bees algorithm (BA). 


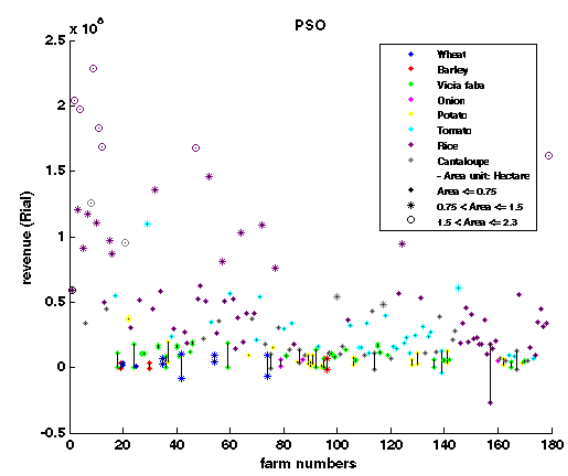

(a)

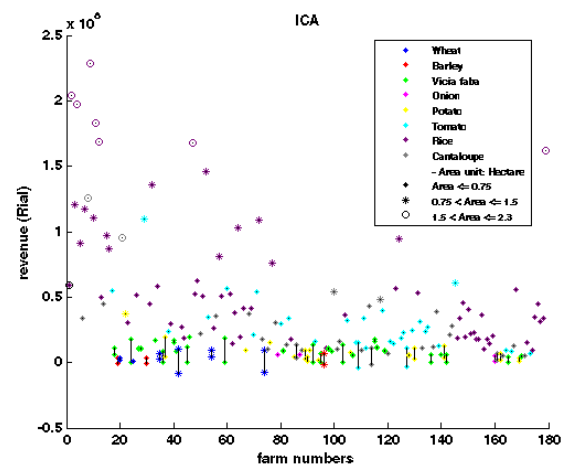

(c)

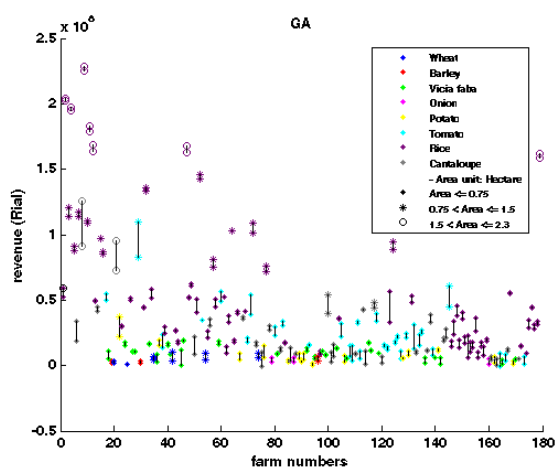

(b)

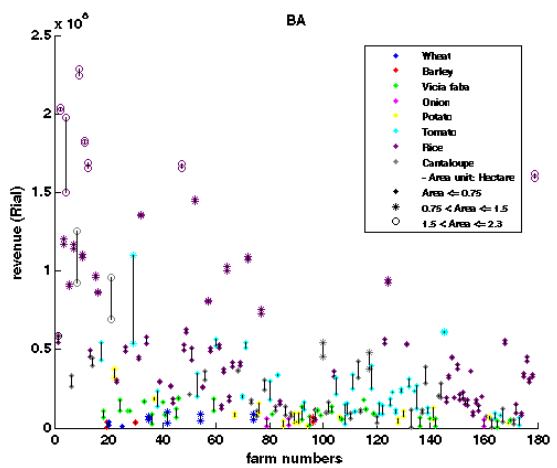

(d)

Figure 10. Profit of lands resulting from different algorithms: (a) PSO, (b) GA, (c) ICA, and (d) BA.

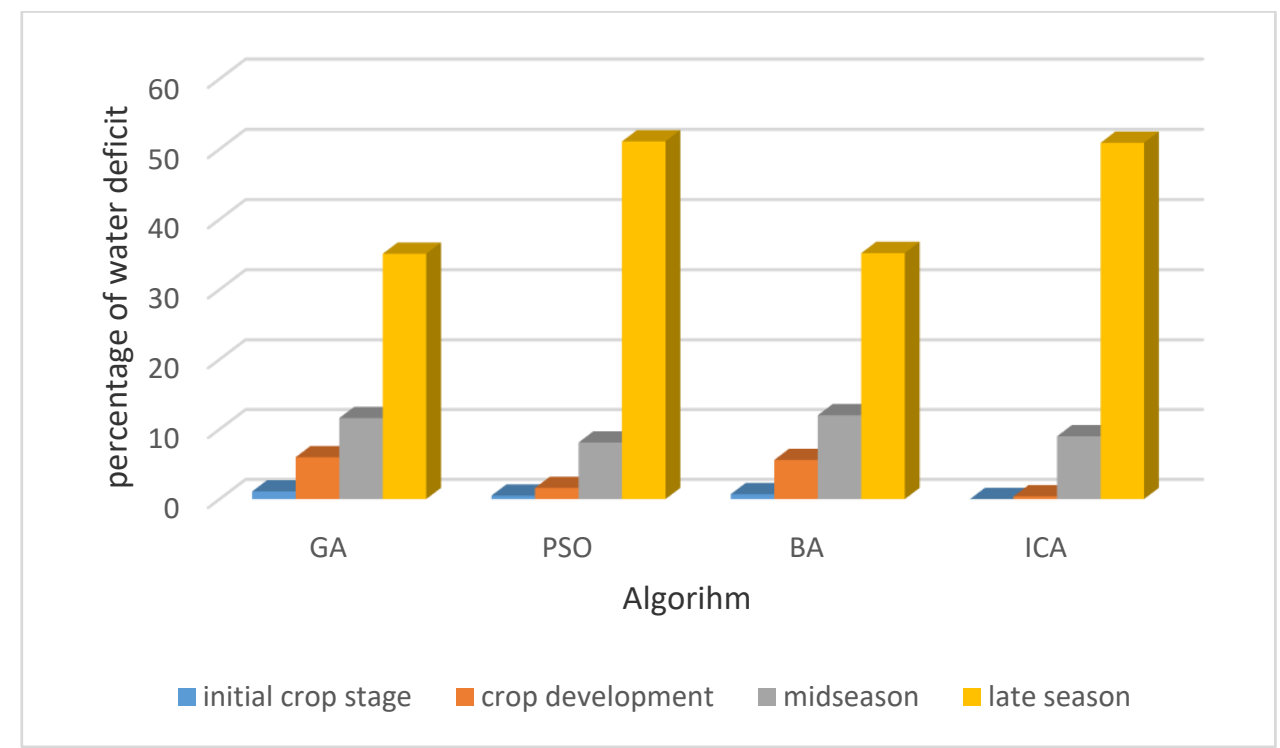

Figure 11. Water reduced from lands in different growth periods by each algorithm.

According to Table 4, the profits from the ICA and PSO algorithms were higher than those from the BA and GA algorithms. Although $12.3 \%$ of the total required water was not available in July, the ICA and PSO algorithms allocated the limited amount of water such that $95.3 \%$ and $94.7 \%$ of the maximum profit were achieved.

In Figure 9, for any of the algorithms, the water volumes related to total irrigation (irrigation water requirement) and optimal irrigation of all lands are shown. For each land, the upper dot shows 
the full irrigation water volume and the lower dot represents the deficit irrigation water volume. The lines in the figure indicate the difference between these two values for each land. For lands where all needed water is allocated, the difference is zero, and the upper and lower dots overlap.

Table 4. Profit resulting from deficit irrigation, using each of the algorithms.

\begin{tabular}{ccc}
\hline $\begin{array}{c}\text { Ratio of Profit Resulting from Each } \\
\text { Algorithm vs. Full Irrigation Profit }\end{array}$ & $\begin{array}{c}\text { Profit Resulting from } \\
\text { Each Algorithm (Rials) }\end{array}$ & Algorithm \\
\hline 86.8 & $5,607,870,134$ & GA \\
94.7 & $6,118,588,536$ & PSO \\
87.9 & $5,682,273,162$ & BA \\
95.3 & $6,157,476,745$ & ICA \\
& $6,461,372,033$ & Full irrigation \\
\hline
\end{tabular}

Table 5. Water deficit values for different crops.

\begin{tabular}{|c|c|c|c|c|c|c|c|c|c|c|}
\hline \multicolumn{11}{|c|}{ Crop Type } \\
\hline \multirow{2}{*}{ Sum } & \multirow{2}{*}{ Cantaloupe } & \multirow{2}{*}{ Rice } & \multirow{2}{*}{ Tomato } & \multirow{2}{*}{ Potato } & \multirow{2}{*}{ Onion } & \multirow{2}{*}{ Vicia Faba } & \multirow{2}{*}{ Barley } & \multirow{2}{*}{ Wheat } & Crop & \multirow{6}{*}{$\begin{array}{c}\text { Percentage } \\
\text { of water } \\
\text { deficit }\end{array}$} \\
\hline & & & & & & & & & Algorithm & \\
\hline- & 21.7 & 1.5 & 16.0 & 71.7 & 73.2 & 41.3 & 42.9 & 37.1 & GA & \\
\hline- & 5.8 & 0.4 & 1.5 & 56.7 & 32.9 & 74.8 & 100 & 98.0 & PSO & \\
\hline- & 19.9 & 1.4 & 17.6 & 32.0 & 91.6 & 50.0 & 37.4 & 40.1 & BA & \\
\hline- & 3.4 & 0 & 3.1 & 43.6 & 34.4 & 92.1 & 100 & 100 & ICA & \\
\hline 87.4 & 13.9 & 42.4 & 10.9 & 3.3 & 0.6 & 9.6 & 2.4 & 4.3 & \multicolumn{2}{|c|}{ Crop area (ha) } \\
\hline
\end{tabular}

As shown in Figure 9, in the PSO and ICA algorithms, respectively, 132 and 133 lands have been irrigated completely, and 46 and 43 lands have not been irrigated at all. Compared with them, the GA and BA resulted in a fairer distribution of water deficits among the lands. The largest differences in water volume observed between total irrigation and deficit irrigation in July, respectively, for GA, PSO, $\mathrm{BA}$, and ICA, were $1420,3785,2143$, and $3785 \mathrm{cu} \mathrm{m}$. The minimum differences were $0.2,0,0.4$, and $0 \mathrm{cu}$ $\mathrm{m}$. , respectively, and the mean of differences for any of the four algorithms was $208 \mathrm{cu} \mathrm{m}$.

In Figure 10, the profit of each land in both cases of full irrigation and deficit irrigation, as proposed by each algorithm, are presented for the month of July. In this figure, similar to Figure 9, the higher and lower points show the profits of the full and deficit irrigations, respectively. The lines indicate the difference between these two values for each land. For any land where all needed water is allocated, the difference is 0 and the lower point is covered by the upper one. In addition, the points' colours represent the crop types, and the points' shapes represent the land areas.

As shown in Figure 10, using the PSO and ICA, the profits do not change for lands with full irrigation, but lands with no allocated water mostly have negative profits. Conversely, using the GA and BA, the total income of the lands is moderately reduced (according to the allocated water, land's yield response, crop type, and land area) but are still positive. However, the total income of all lands in the PSO and ICA are higher than that of the other two algorithms.

As shown in Figure 10, considering the high price of rice and larger size of the rice fields, these lands have the highest income. Considering this and the high cost of rice production, with the deficit irrigation of the rice, the income is reduced radically. Therefore, the ICA and PSO algorithms did not reduce the irrigation share of these lands, whereas an opposite decision is taken for Vicia faba, wheat, and barley. These crops have the lowest income among others in the study area. Therefore, the ICA and PSO algorithms proposed the most intensive water deficit for lands with these crops.

In Figure 10, the PSO and ICA algorithms allocated the water deficit mostly to the lands where their profits, even in the case of full irrigation, are often less than those of others. The low income of these lands is due to their crop type and a small area. As shown in Figure 10, the PSO and ICA algorithms allocated all water deficit to lands smaller than $0.75 \mathrm{ha}$, except for a few lands with areas of less than 1.5 ha. The product of these lands, with areas of less than $1.5 \mathrm{ha}$, is wheat, which has a 
low income. In fact, economic profit can be maximised if deficit irrigation is applied mostly to lands with smaller areas or low-income products, and other lands are irrigated completely. The results of the PSO and ICA algorithms proved this. Although some lands had a negative profit, the total profit of all lands in these algorithms are higher than those from the BA algorithm. In addition to these factors, the growth period also has a significant effect on maximising economic profit. This issue is addressed in the following. In Figure 11, for each algorithm, the amounts of water reduced from the lands in different growth periods are presented.

The yield response factors of most crops in the late season stage are much lower than those in the other stages, i.e., the crops are more resistant to water shortage at this stage. Therefore, reducing the water of the lands with crops at this stage is economically reasonable. This finding is consistent with the results shown in Figure 11: The percentage of water deficit allocated to the lands with crops at the final stage is much more than the lands with crops at other growth stages. In the PSO and ICA algorithms, this is more evident, which is the main reason for the higher profit gains in these algorithms. The yield response factor of the initial stage is less than that of the crop-development and midseason stages, i.e., the crops are more resistant to water shortage at this stage compared with the other two mentioned stages. However, as shown in Figure 11, the water deficit allocated to crops of this stage is lower than that in the other two stages. The reason for this can be the relation of the crop types with deficit irrigation (Table 5).

In the study area, the peas and garlic products are usually harvested before July, according to their cultivation date. Therefore, Table 5 does not include any values for these crops. In all algorithms, the percentages of water deficit allocated to lands with wheat, barley, Vicia faba, onion, and potatoes are much higher than those of lands with tomatoes, rice and cantaloupe. This condition is much more evident for the PSO and ICA algorithms. In the ICA algorithm, for wheat and barley, the percentage of water deficit is $100 \%$. Instead, although rice covers $42.4 \%$ of the total area and its water need in July is the highest among all the crops, the percentage of water deficit is 0 . Similar to rice, tomatoes and cantaloupe cover the largest areas after rice and their water needs are higher than those of the other crops. However, the water deficit allocated to them is much lower than those of other crops. The same has happened regarding the PSO as well.

There are two reasons for such results and allocations. The yield response factors of wheat, barley, Vicia faba, onion, and potatoes are much lower than those of other crops in most growth stages. That is, these five crops are less sensitive to water deficit. Therefore, most of the water deficit should be allocated to them, as shown in Table 5. Another reason is the difference in profit and cost of different crops. The profit-to-cost ratio of tomatoes, rice, and cantaloupe are much higher than that of other crops. Therefore, algorithms should not degrade such crops. This issue is evident in Table 5.

\section{Comparison and Evaluation of Algorithm Performance}

In this section, the solution of the AW problem by the meta-heuristic algorithms are evaluated and compared.

- Fitness function of algorithms

As presented in Table 4, the algorithms in order of economic profits are ICA, PSO, BA, and GA. The profit derived from the ICA algorithm is, respectively, 1.006, 1.083, and 1.098 times more than those of the PSO, BA, and GA algorithms.

- Convergence of algorithms

Figure 12 illustrates and compares the convergence speed/trend of the four algorithms. As mentioned, from 10 different executions of each algorithm, the best one is chosen to represent the results and evaluate the algorithm. The convergence diagrams presented here are also related to those best executions. 


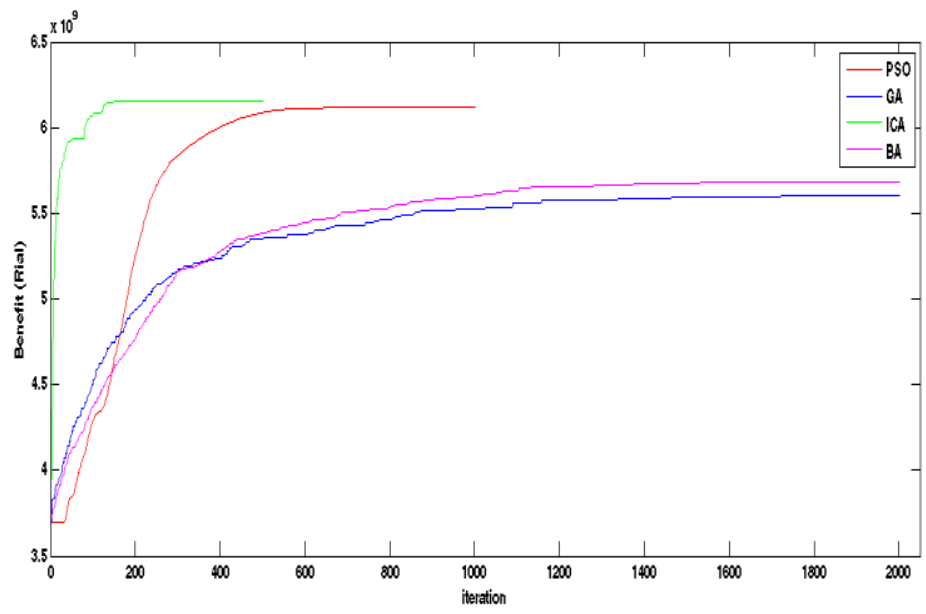

Figure 12. Convergence speed/trend of algorithms.

According to the diagrams of Figure 12, in all four algorithms, the convergence rate is extremely high in the initial iterations; then, gradually the rate is reduced, and the algorithms eventually converge. The convergence of the GA, PSO, and BA algorithms are rather gradual, but in the ICA algorithm, there are three stages of sudden convergence. As shown in Figure 12, the ICA and then PSO have higher convergence rates than the others. The iteration axis is magnified for the ICA and then PSO to show their convergence trend in greater detail.

As shown in the last iterations of the GA, there is always a curiosity that the best solutions might still be improved if the algorithm runs for a longer period. As mentioned in the definition of the meta-heuristic algorithms, there is no certainty about reaching the ultimate optimal solution. However, the algorithms can approximate it very well in an acceptable time. In this study, the stopping condition was to achieve a relative stability in the best-found solutions.

- Repeatability test of algorithms

The variances of the normalised benefit values for all algorithms in 10 runs are presented in Table 6. In fact, each of the solutions contains 179 decision parameters (amount of water allocated to each one of the 179 lands is a decision parameter), and each parameter can take any value from a continuous range of allocated water values. As a result, the number of possible solutions becomes extremely large. In other words, any two solutions, even when obtained from a single algorithm, are most probably different.

Table 6. Variances of normalised fitness function values in 10 executions of each algorithm.

\begin{tabular}{cc}
\hline Variance & Algorithm \\
\hline 0.126 & GA \\
0.119 & PSO \\
0.139 & BA \\
0.079 & ICA \\
\hline
\end{tabular}

The variance values shown in Table 6 indicate the relative stability of the algorithms. In this assessment, the stability of the ICA algorithm is more than that of the others. Thereafter, the PSO and GA seem to be more repeatable and stable than the BA.

As indicated in the methods section, the ability of an algorithm to reach similar solutions can be considered a measure of repeatability. Figure 13 shows the variance of the normalised allocated water to each farm by any algorithm in 10 runs. 


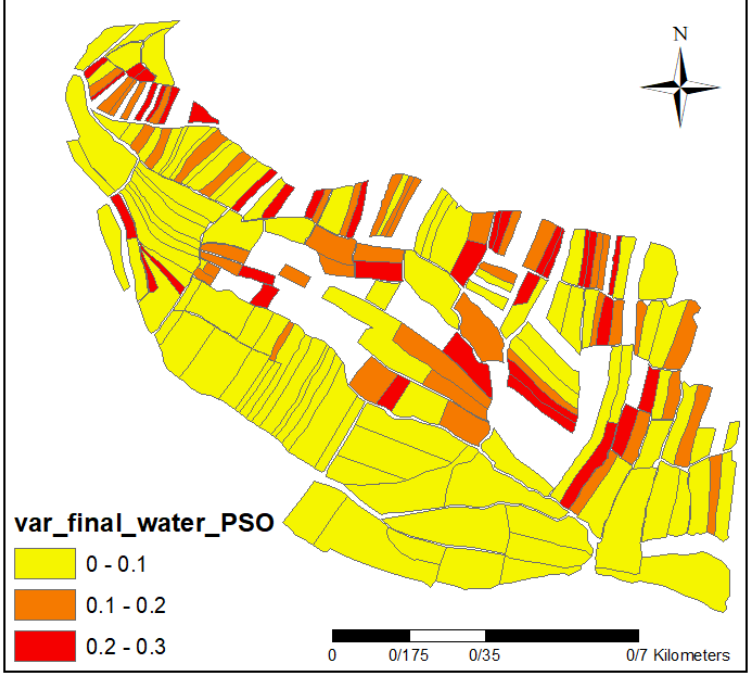

(a)

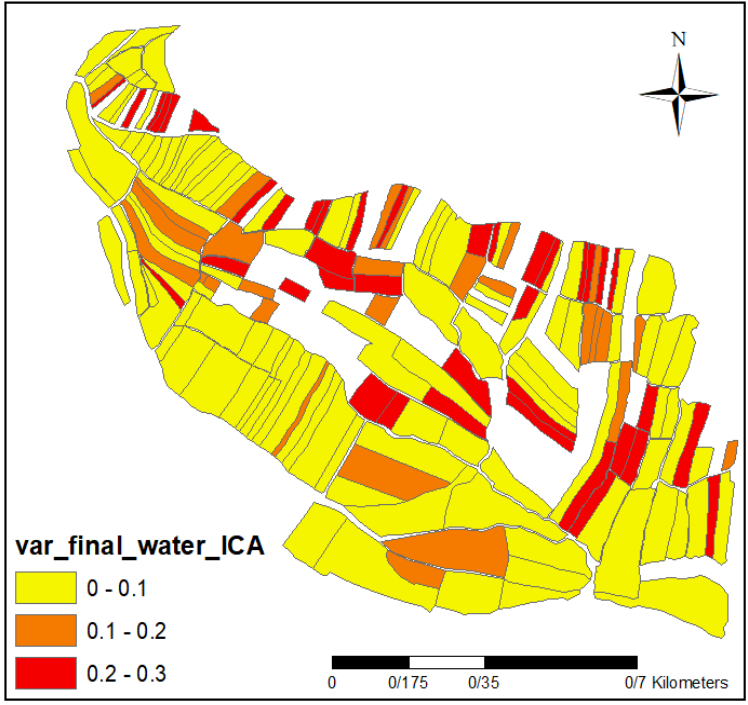

(c)

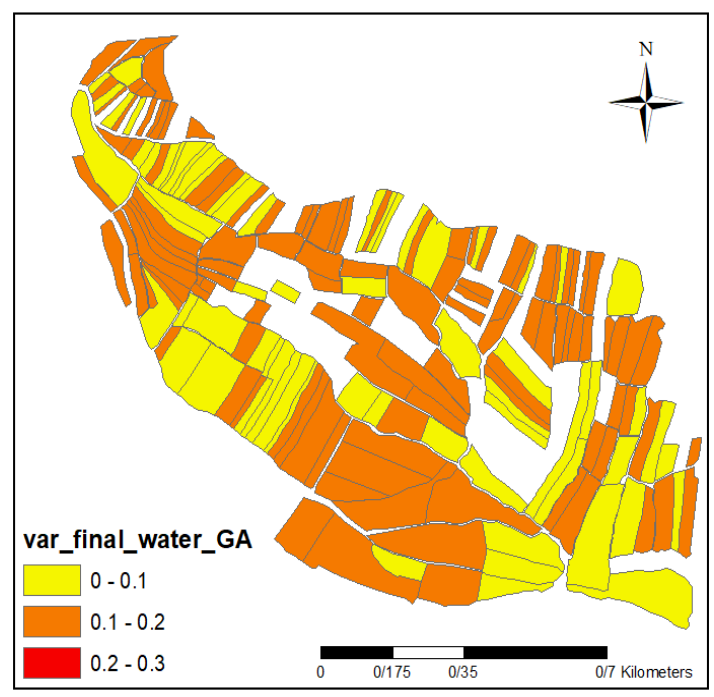

(b)

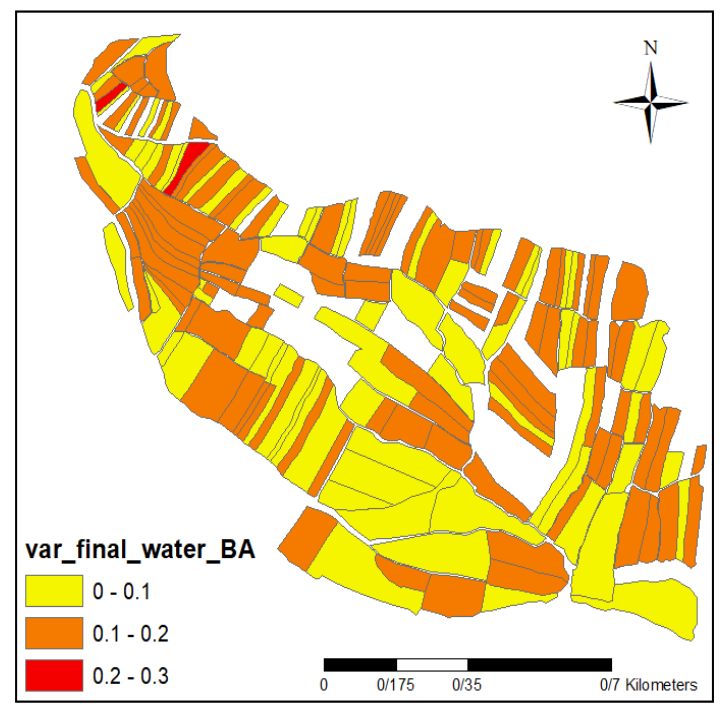

(d)

Figure 13. Variances of normalised allocated water to each farm in 10 executions by the algorithms: (a) PSO, (b) GA, (c) ICA, and (d) BA.

Figure 13 shows acceptable levels of the algorithm's stability in achieving similar solutions in 10 different executions. The minimum, maximum, and mean values of the variance of the normalised allocated water to each farm by BA in 10 runs are $0.073,0.206$, and 0.111 , respectively. For the GA, these values are $0.064,0.193$, and 0.114 . For the PSO, they are $0,0.278$, and 0.090 , and finally for the ICA, they are $0,0.278$, and 0.088 , respectively. In comparison, the ICA and then the PSO showed better results than the other two algorithms with regard to the average of the variances. This result is similar to the result of algorithm comparison regarding the stability of objective function.

- Runtime of algorithms

In this section, the time to reach a specified objective function value (here, reaching 5,500,000,000 Rials) is examined. The parameters of the algorithms are set equal to those of the previous steps. Again, the mean of runtime for 10 runs is used. The results of this test are presented in Table 7 . This 
assessment showed that the ICA algorithm was followed by the PSO algorithm, which performed significantly higher than the other two algorithms.

Table 7. Runtime of algorithms (reaching a specified value is the stopping condition).

\begin{tabular}{cc}
\hline Runtime (Second) & Algorithm \\
\hline 240 & GA \\
30 & PSO \\
109 & BA \\
7 & ICA \\
\hline
\end{tabular}

In the following, to compare the runtime of the algorithms, the best fitness-function values found by the algorithms in a specified time are compared. Each algorithm is executed 10 times, each time for $60 \mathrm{~s}$. In each execution, the best-found value is regarded as the final profit. Then, the maximum and average of the final profits in 10 executions of the algorithms are used as parameters for comparison (Table 8).

Table 8. Maximum and average of profits in 10 executions of the algorithms (with $60 \mathrm{~s}$ runtime as stopping condition).

\begin{tabular}{ccc}
\hline $\begin{array}{c}\text { Average of Profit in } \mathbf{1 0} \\
\text { Executions (Rials) }\end{array}$ & $\begin{array}{c}\text { Maximum of Profit in 10 } \\
\text { Executions (Rials) }\end{array}$ & Algorithm \\
\hline $5,387,836,327$ & $5,444,038,703$ & GA \\
$5,935,118,598$ & $6,064,733,606$ & PSO \\
$5,198,019,407$ & $5,294,260,194$ & BA \\
$6,087,052,792$ & $6,137,231,868$ & ICA \\
\hline
\end{tabular}

Both the highest and average profits achieved by the ICA algorithm are higher than those of the other algorithms. The PSO algorithm is in the next rank. Contrary to the results in Table 4, in this evaluation, the highest and average profits of the BA algorithm were less than those of the GA. The reason for this result is shown in Figure 12, where the BA algorithm exhibits less convergence in its early iterations than the GA.

- Modelling complexity and ease of use of algorithms

In GA and ICA, seven different parameters must be set before the implementation, using methods such as trial and error, neural network, and others. Compared with them, in PSO and BA, eight parameters should be set by the user. Thus, from the user's point of view, the complexity of the PSO and BA are slightly more than those of the GA and ICA.

Another issue related to the complexity of the algorithms is the number of operators that should be defined for the problem in hand. In the modelling of the BA and PSO, only one important and complex operator should be defined (the neighbourhood operators of the BA and velocity operator of the PSO). Compared with them, in GA, two operators of crossover and mutation have to be defined. Similarly, in ICA, three operators of empire formation, assimilation, and imperialistic competition have to be defined. Thus, from the authors' point of view, the BA, PSO, and GA are respectively easier than the ICA to apply on the AW problem.

- Ranking of algorithms using TOPSIS method

In this section, the algorithms are ranked according to the described criteria using the TOPSIS method. This ranking is in accordance with the experiment of this study for the irrigation-water allocation problem. First, the decision matrix and parameter weights should be determined. In the decision matrix in Table 9, the weights of the parameters are defined based only on the experience and opinion of the authors. 
Table 9. Decision matrix and criteria weights needed for TOPSIS model.

\begin{tabular}{cccccc}
\hline $\mathbf{0 . 0 5}$ & $\mathbf{0 . 1 0}$ & $\mathbf{0 . 2 5}$ & $\mathbf{0 . 1 0}$ & $\mathbf{0 . 5 0}$ & Weight \\
\hline $\begin{array}{c}\text { Number of } \\
\text { Algorithm } \\
\text { Operators }\end{array}$ & $\begin{array}{c}\text { Number of } \\
\text { Algorithm } \\
\text { Parameters }\end{array}$ & $\begin{array}{c}\text { Variance (as a } \\
\text { Measure of } \\
\text { Robustness) }\end{array}$ & $\begin{array}{c}\text { Runtime to Reach a } \\
\text { Defined Precision } \\
\text { (Second) }\end{array}$ & $\begin{array}{c}\text { Final } \\
\text { Optimums } \\
\text { Found (Rials) }\end{array}$ & $\begin{array}{c}\text { Choice of } \\
\text { Algorithm }\end{array}$ \\
\hline 2 & 7 & 0.126 & 240 & $5,607,870,134$ & GA \\
1 & 8 & 0.119 & 30 & $6,118,588,536$ & PSO \\
1 & 8 & 0.139 & 109 & $5,682,273,162$ & BA \\
3 & 7 & 0.079 & 7 & $6,157,476,745$ & ICA \\
\hline
\end{tabular}

In the second column of Table 9, the best answer among the 10 independent executions of each algorithm is presented (as extracted from Table 4). The third column shows the runtime needed to reach a particular value of the objective function (a specific economic benefit), as extracted from Table 7 . The variances of the normalised benefit values for 10 runs of each algorithm (extracted from Table 6) are also presented in the fourth column. The last two columns are related to the complexity of using and modelling each algorithm and are extracted from the previous section.

Thereafter, the relative closeness (CL) for each algorithm is calculated. An option with a higher CL is regarded as a better choice. In Table 10, the ranking of algorithms resulting from the TOPSIS method is presented, where the ICA has received a higher rank than the others.

Table 10. Ranking of algorithms based on TOPSIS method.

\begin{tabular}{ccc}
\hline CL & Choice of Algorithm & Rank \\
\hline 0.8114 & ICA & 1 \\
0.6690 & PSO & 2 \\
0.4192 & BA & 3 \\
0.1609 & GA & 4 \\
\hline
\end{tabular}

- Evaluation and comparison of proposed method with conventional AW method

In this section, the allocation of available water is conducted on the basis of land areas, and the results are compared with those of the ICA algorithm. The profit achieved by the area-based AW method was 1,297,109,002 Rials, which is much lower than the profit related to the ICA algorithm $(6,157,476,745$ Rials). The reason for the large difference is that in the simple area-based AW, the crop types and planting periods are not considered. Figure 14 shows the crop efficiency ( $Y a / \Upsilon p)$ of each land, resulting from the area-based AW and ICA-based AW methods.

In the area-based $\mathrm{AW}$, the highest, mean, and lowest efficiency are $1,0.79$, and 0.51 , respectively. In the ICA-based method, these are $1,0.94$, and 0.33 , respectively. The minimum crop efficiency of the ICA-based method is smaller than that of the area-based AW because in the ICA-based method, some lands are not irrigated at all, in July. On the other hand, the mean crop efficiency for all lands in the ICA is much higher, which is the main reason for the higher income. In fact, in ICA, besides the area, the crop type and growth stage (according to the planting date) are also considered, and the water is allocated such that the total economic income is maximised. 


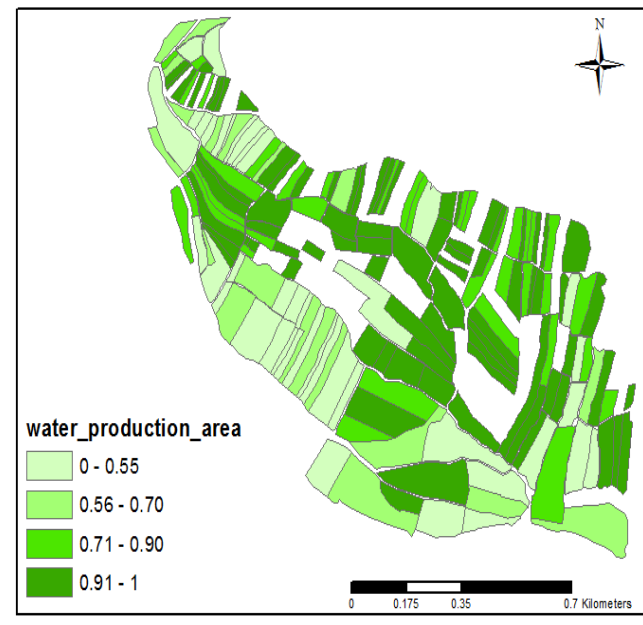

(a)

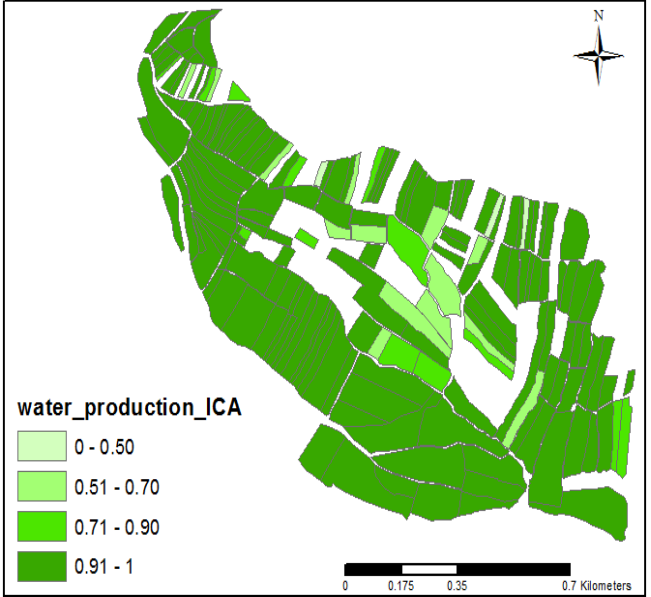

(b)

Figure 14. Crop efficiencies $\left(Y_{p} / Y_{a}\right)$ resulting from (a) area-based AW and (b) ICA-based AW.

\section{Discussion}

As mentioned, the objective of this study was to propose a dynamic model for optimal AW to agricultural lands, considering the cultivation conditions and aiming at maximising the economic profit. The proposed model considers the amount of available water, type and price of planted crops, planting date and growth stage of the crops, and other relevant data. It uses meta-heuristic algorithms to optimise AW. Despite numerous searches, the authors did not succeed in finding any previous study that is similar to the present study. Therefore, it was not possible to numerically compare the results of the present study with those of the previous ones. In previous studies [2,21,75-81], the AW is carried out between different sectors in the region, between the catchment areas, between irrigation networks, and between cultivated crops (e.g., the AW to all lands cultivated with wheat in a region). In some relatively similar studies, the water is allocated at farm level, but for the entire growing season and not on a monthly basis. In such static models, the temporal conditions such as planting date and crop growth-stage in each month (as the planning time unit) are not considered. Therefore, the unique feature of this study is the dynamic and month-by-month AW to the lands to maximise the economic profit of all lands.

According to Table 5 and Figure 11, the economic profit is greater if the water deficit is imposed mostly on crops with lower cost and income, and also on crops with lower yield response factors considering their growth period. In general, according to the results, economic profit increases through the following strategies: Applying deficit irrigation on lands with crop types less sensitive to water shortage, applying deficit irrigation on lands where their crops at that growth stage are less sensitive to water shortage, applying deficit irrigation on lands with crop types that have a lower cost and income, and applying deficit irrigation on smaller lands.

As shown in Figure 9, the results of the allocation by PSO and ICA are highly similar to each other. The results of the GA and BA are also rather similar. In GA and BA, the amount of water deficit is distributed almost fairly among most of the lands (according to the type of crop, its growth period, and the farm area). On the other hand, in the implementation of ICA and PSO, some lands are well irrigated to the price of other lands being dried. Comparing the results of PSO and ICA with those of GA and BA, the deficit irrigation of all lands does not seem to be an economically good strategy. Instead, to achieve higher economic profit from the collection of all lands, irrigating some of the more profitable lands completely and drying the less profitable ones is an effective strategy. However, some farmers are obviously dissatisfied with this approach. Other actions can be proposed in this regard. For example, the economic loss of such farmers can be compensated by insurance policies. 
In fact, not irrigating (drying) some lands, for the sake of greater economic profit, is a complex issue. Agriculture has social and cultural aspects besides the economic aspect. Even when compensation is paid by the insurance companies, the farmers might not agree to leave their lands to dry. Based on this interpretation, although generating lower profits than the ICA and PSO, the BA and GA algorithms still seem to be more favourable because they do not suggest drying any land.

To prevent farmers' dissatisfaction, some deficit irrigation ratios can be considered in the model to limit the amount of water deficit imposed on each land. Such ratios should be considered so that the total amount of water deficit can be greater than the water shortage in the irrigation period. Balancing the irrigation deficit imposed on lands and preventing the drying of a number of lands can be considered in the optimisation both as a constraint or as an objective function. However, such an approach was not considered in this study. From an economic point of view, it would certainly be beneficial to dry a number of lands and allocate the water to the more profitable lands. In fact, in the current regime of regional water organisations in Iran, one of the water management policies is to stop the irrigation of the less profitable lands and compensate it by direct payment.

In the present study, a month is regarded as the time step for irrigation planning. A shorter time step, such as a week or 10 days, might bring better results. By considering longer irrigation periods such as a season, we can ignore the dynamic conditions and growth periods of the plants. For example, the entire cultivation-to-harvest phase for tomato takes approximately three to four months. If we select season as the irrigation period, then we have practically all four growth phases in one season. In such a method, the crops' growth phases are not considered in the AW. The researchers recommend even shorter irrigation periods, such as a week. Such periods are closer to the reality of farm water allocation from the point of view of managers or farmers. For example, in the study area, tomato is irrigated every week. In this study, the schedule of dates and irrigation rates during the irrigation planning period (month) are not specified. In other words, in this research, it is determined how much water is allocated to each land in the whole month. However, the irrigation dates during the month and irrigation rate in those dates are not considered. By considering shorter irrigated periods such as a week, we can resolve this problem.

In the rest of this section, the performances of the used meta-algorithms are discussed. The considered AW problem was solved using four meta-heuristic algorithms, and the performances of those algorithms for the specific implementation of this study were evaluated. Then, the meta-heuristic algorithms were ranked using the TOPSIS decision-making model based on the parameters of fitness function, stability, run time, and complexity of modelling and use. According to the results of TOPSIS, the algorithms in order of priority are ICA, PSO, BA, and GA.

Regardless of the implementation results, the following conceptual issues can affect the performance of the algorithms: Essential structure of algorithms and problem to be solved. For example, the solution improvement in the PSO and ICA algorithms is based on the motion of the solutions in a continuous space. As a result, these algorithms are more suitable for solving continuous problems such as $\mathrm{AW}$; the next issue is the theoretical foundation of the algorithms themselves. According to the authors' experience, some algorithms have stronger operators for the exploration and exploitation of the search space and are naturally better at solving complex problems. For example, the PSO combines information from two promising solutions (the best position of the particle and the best position of all particles) for exploitation. In the GA, the two parent solutions are crossed over to generate a new solution, which cannot be considered a direct exploitation of the parent solutions. However, this does not imply that the PSO is always superior to the GA algorithm.

One of the important issues in using meta-heuristic algorithms for such problems is the reliability of research results for other areas. In this study, an optimisation approach was proposed and tested for the allocation of agricultural water with the aim of maximising economic profit, without considering any specific condition of the study area. Consequently, the model is not strongly dependent on the study area. However, to compare and evaluate the algorithms, the results of implementing them on the case study are used. Although by changing the region the results may change slightly, the 
results of this study can be used for other locations with a certain level of confidence. Wolpert and Macready [82] showed that no general classification exists for the performance of algorithms. In other words, in the comparison of meta-heuristic algorithms, the results depend strongly on the type of optimisation problem. Conversely, by changing the study area, the results should not change significantly. For example, in this study, the changes in the study area, number of lands, crop types, and growth period changes. However, the model and results of comparing the algorithms do not seem to change dramatically. The researchers tested and evaluated these algorithms, first on presumed data, and then on the real data. The results related to the presumed data were approximately the same as those of the actual data. Owing to the paper length limitation and similarity of the outcomes, the results of the presumed data are not presented in this paper.

\section{Conclusions}

The main goal of this study was to represent the AW at farm level as an optimisation problem while considering the data related to the types and growth levels of the crops and to solve it using some meta-heuristic algorithms. In this study, due to the complexity and nonlinearity of the objective function and the extent of the search space, some meta-heuristic algorithms were used to optimise the AW to land units. A second objective was to compare the performances of those algorithms for the considered problem. In the proposed method of this study, the water needed for each farm during the considered month was determined to maximise the profit of all farms. In practice, the land income depends on parameters such as crop type, crop income (income-to-cost ratio), crop sensitivity to water deficit in different growth periods, and crop cultivation area. The results showed that the proposed method has greatly presented the role of these parameters in increasing overall land profits.

In general, as confirmed by TOPSIS, the ICA and PSO were superior to the GA and BA algorithms in many aspects. The only problem is that they allocated no water to some farms, which certainly results in the dissatisfaction of the related farmers. A positive aspect of the GA and BA is the optimisation of the total income whilst allocating water to most farms, which results in the satisfaction of most of the farmers. However, this is achieved at the expense of lower income for all farms. Each of these scenarios, i.e., higher economic profitability or greater social satisfaction, can be a priority for the decision makers.

The model and method proposed in this study can be used by the farmers and agricultural managers even for cultivation planning in the coming years. Considering their land areas, the farmers will know about the risks of planting different crop types. This condition means that they gradually avoid the crops that probably should be left unirrigated in some growth periods. This propels farmers towards more economic crop types with less water requirements. The managers also use the results of the AW in one year to improve the scenario in the coming years. They can encourage farmers towards more economic crop types with less water requirements. In addition, they can estimate the amount of compensation that should be paid to the farmers of unirrigated lands. With proper planning, in the long term, fewer lands will be left unirrigated, less compensation has to be made, and the general income of all lands will be increased.

For simplicity, some issues and aspects were not considered in this study. The development of the method to incorporate these aspects can be the subject of future work. Usually, the farm-based water requirements are calculated on the basis of parameters such as effective rainfall, leaching and irrigation efficiency. Here, due to the small size of the study area and trivial variation of these parameters between the lands, these parameters are considered constant in the entire area. In addition, the water requirements of plants are affected by a number of other factors, such as the land slope and water stored in the soil, which depends on the type of soil, plant root length, amount, and time of previous irrigation. Incorporation and detailed calculation of those factors can be an interesting subject for future research.

Besides the income, other criteria such as strategic crop types, social factors, water price, and farmers' satisfaction can be considered in the optimisation. The irrigation water can be obtained from several resources in the study area. Such a situation can happen in many other studies as well. 
Therefore, as a continuation of this study, a model for the AW from all available resources to the lands can be developed. In such an allocation, spatial factors of distance, topography, and access to different resources, such as dams, wells, pumping stations, and canals, should be considered. In such an optimisation problem, aside from the income maximisation, other criteria such as distance from the resources, water losses, or water transfer efficiency can be considered either as objective functions or as constraints.

Author Contributions: B.S. and M.S.M. conceived, designed, and performed the experiments; they analysed the data and wrote the paper with contribution from B.P.; B.P. and A.M.A. professionally revised the manuscript. The manuscript was discussed and reviewed by all of authors as they enhanced the context with sufficient references.

Funding: The research is supported by the Centre for Advanced Modelling and Geospatial Information Systems (CAMGIS), University of Technology Sydney under grant numbers: 323930, 321740.2232335; 321740.2232424 and 321740.2232357. This research was also supported by Researchers Supporting Project number RSP-2019/14, King Saud University, Riyadh, Saudi Arabia.

Conflicts of Interest: The authors declare no conflict of interest.

\section{References}

1. Alvarez, J.F.O.; de Juan Valero, J.A.; Martín-Benito, J.M.T.; Mata, E.L. MOPECO: An economic optimization model for irrigation water management. Irrig. Sci. 2004, 23, 61-75. [CrossRef]

2. Dai, Z.; Li, Y. A multistage irrigation water allocation model for agricultural land-use planning under uncertainty. Agric. Water Manag. 2013, 129, 69-79. [CrossRef]

3. Li, M.; Guo, P. A multi-objective optimal allocation model for irrigation water resources under multiple uncertainties. Appl. Math. Model. 2014, 38, 4897-4911. [CrossRef]

4. Raes, D.; Geerts, S.; Kipkorir, E.; Wellens, J.; Sahli, A. Simulation of yield decline as a result of water stress with a robust soil water balance model. Agric. Water Manag. 2006, 81, 335-357. [CrossRef]

5. Steduto, P.; Hsiao, T.C.; Fereres, E.; Raes, D. Deficit Irrigation Practices; FAO: Rome, Italy, 2002.

6. Khan, S.; O'Connell, N.; Wang, Z. Irrigation Advisory Services and Participatory Extension in Irrigation Management; Workshop organised by FAO-ICID; FAO: Rome, Italy, 2002.

7. Ortega, J.; De Juan, J.; Tarjuelo, J. Improving water management: The irrigation advisory service of Castilla-La Mancha (Spain). Agric. Water Manag. 2005, 77, 37-58. [CrossRef]

8. Li, W.; Li, Y.; Li, C.; Huang, G. An inexact two-stage water management model for planning agricultural irrigation under uncertainty. Agric. Water Manag. 2010, 97, 1905-1914. [CrossRef]

9. Davijani, M.H.; Banihabib, M.; Anvar, A.N.; Hashemi, S. Optimization model for the allocation of water resources based on the maximization of employment in the agriculture and industry sectors. J. Hydrol. 2016, 533, 430-438. [CrossRef]

10. Divakar, L.; Babel, M.S.; Perret, S.; Gupta, A.D. Optimal allocation of bulk water supplies to competing use sectors based on economic criterion-An application to the Chao Phraya River Basin, Thailand. J. Hydrol. 2011, 401, 22-35. [CrossRef]

11. Babel, M.; Gupta, A.D.; Nayak, D. A model for optimal allocation of water to competing demands. Water Resour. Manag. 2005, 19, 693-712. [CrossRef]

12. Chang, F.-J.; Wang, Y.-C.; Tsai, W.-P. Modelling intelligent water resources allocation for multi-users. Water Resour. Manag. 2016, 30, 1395-1413. [CrossRef]

13. Wang, Z.; Yang, J.; Deng, X.; Lan, X. Optimal water resources allocation under the constraint of land use in the Heihe River Basin of China. Sustainability 2015, 7, 1558-1575. [CrossRef]

14. Song, W.-Z.; Yuan, Y.; Jiang, Y.-Z.; Lei, X.-H.; Shu, D.-C. Rule-based water resource allocation in the Central Guizhou Province, China. Ecol. Eng. 2016, 87, 194-202. [CrossRef]

15. Rees, H.; Holmes, M.G.; Fry, M.; Young, A.R.; Pitson, D.; Kansakar, S. An integrated water resource management tool for the Himalayan region. Environ. Model. Softw. 2006, 21, 1001-1012. [CrossRef]

16. Schlüter, M.; Savitsky, A.G.; McKinney, D.C.; Lieth, H. Optimizing long-term water allocation in the Amudarya River delta: A water management model for ecological impact assessment. Environ. Model. Softw. 2005, 20, 529-545. [CrossRef] 
17. McKinney, D.C.; Cai, X.; Maidment, D.R. A prototype GIS-based decision support system for river basin management. In Proceedings of the ESRI International User Conference Proceedings, San Diego, CA, USA, 8-11 July 1997.

18. Yazdi, A.B.; Araghinejad, S.; Nejadhashemi, A.P.; Tabrizi, M.S. Optimal water allocation in irrigation networks based on real time climatic data. Agric. Water Manag. 2013, 117, 1-8.

19. Shangguan, Z.; Shao, M.; Horton, R.; Lei, T.; Qin, L.; Ma, J. A model for regional optimal allocation of irrigation water resources under deficit irrigation and its applications. Agric. Water Manag. 2002, 52, 139-154. [CrossRef]

20. Vaghefi, S.A.; Mousavi, S.; Abbaspour, K.; Srinivasan, R.; Arnold, J. Integration of hydrologic and water allocation models in basin-scale water resources management considering crop pattern and climate change: Karkheh River Basin in Iran. Reg. Environ. Chang. 2015, 15, 475-484. [CrossRef]

21. Niu, G.; Li, Y.; Huang, G.; Liu, J.; Fan, Y. Crop planning and water resource allocation for sustainable development of an irrigation region in China under multiple uncertainties. Agric. Water Manag. 2016, 166, 53-69. [CrossRef]

22. Li, M.; Guo, P.; Singh, V.P. An efficient irrigation water allocation model under uncertainty. Agric. Syst. 2016, 144, 46-57. [CrossRef]

23. Montazar, A.; Rahimikob, A. Optimal water productivity of irrigation networks in arid and semi-arid regions. Irrig. Drain. J. Int. Comm. Irrig. Drain. 2008, 57, 411-423. [CrossRef]

24. Reca, J.; Roldán, J.; Alcaide, M.; López, R.; Camacho, E. Optimisation model for water allocation in deficit irrigation systems: I. Description of the model. Agric. Water Manag. 2001, 48, 103-116. [CrossRef]

25. Kuo, S.-F.; Merkley, G.P.; Liu, C.-W. Decision support for irrigation project planning using a genetic algorithm. Agric. Water Manag. 2000, 45, 243-266. [CrossRef]

26. Haq, Z.U.; Anwar, A.A. Irrigation scheduling with genetic algorithms. J. Irrig. Drain. Eng. 2010, 136, 704-714. [CrossRef]

27. Hassan-Esfahani, L.; Torres-Rua, A.; McKee, M. Assessment of optimal irrigation water allocation for pressurized irrigation system using water balance approach, learning machines, and remotely sensed data. Agric. Water Manag. 2015, 153, 42-50. [CrossRef]

28. Nagesh Kumar, D.; Raju, K.S.; Ashok, B. Optimal reservoir operation for irrigation of multiple crops using genetic algorithms. J. Irrig. Drain. Eng. 2006, 132, 123-129. [CrossRef]

29. Sharif, M.; Wardlaw, R. Multireservoir systems optimization using genetic algorithms: Case study. J. Comput. Civ. Eng. 2000, 14, 255-263. [CrossRef]

30. Wardlaw, R.; Bhaktikul, K. Application of genetic algorithms for irrigation water scheduling. Irrig. Drain. J. Int. Comm. Irrig. Drain. 2004, 53, 397-414. [CrossRef]

31. Wardlaw, R.; Sharif, M. Evaluation of genetic algorithms for optimal reservoir system operation. J. Water Resour. Plan. Manag. 1999, 125, 25-33. [CrossRef]

32. Wu, Z.Y.; Simpson, A.R. Competent genetic-evolutionary optimization of water distribution systems. J. Comput. Civ. Eng. 2001, 15, 89-101. [CrossRef]

33. Izquierdo, J.; Montalvo, I.; Pérez, R.; Tavera, M. Optimization in water systems: A PSO approach. In Proceedings of the 2008 Spring Simulation Multiconference, Ottawa, ON, Canada, 14-17 April 2018; pp. 239-246.

34. Nagesh Kumar, D.; Janga Reddy, M. Multipurpose reservoir operation using particle swarm optimization. J. Water Resour. Plan. Manag. 2007, 133, 192-201. [CrossRef]

35. Noory, H.; Liaghat, A.M.; Parsinejad, M.; Haddad, O.B. Optimizing irrigation water allocation and multicrop planning using discrete PSO algorithm. J. Irrig. Drain. Eng. 2011, 138, 437-444. [CrossRef]

36. Ostadrahimi, L.; Mariño, M.A.; Afshar, A. Multi-reservoir operation rules: Multi-swarm PSO-based optimization approach. Water Resour. Manag. 2012, 26, 407-427. [CrossRef]

37. Rai, P.K.; Dhanya, C.; Chahar, B. A PSO approach for optimum design of dynamic inversion controller in water distribution systems. J. Water Supply Res. Technol. Aqua 2016, 65, 570-581. [CrossRef]

38. SaberChenari, K.; Abghari, H.; Tabari, H. Application of PSO algorithm in short-term optimization of reservoir operation. Environ. Monit. Assess. 2016, 188, 667. [CrossRef] [PubMed]

39. Shourian, M.; Mousavi, S.; Tahershamsi, A. Basin-wide water resources planning by integrating PSO algorithm and MODSIM. Water Resour. Manag. 2008, 22, 1347-1366. [CrossRef] 
40. Zhang, J.; Wu, Z.; Cheng, C.; Zhang, S. Improved particle swarm optimization algorithm for multi-reservoir system operation. Water Sci. Eng. 2011, 4, 61-73.

41. Chang, J.-x.; Bai, T.; Huang, Q.; Yang, D.-W. Optimization of water resources utilization by PSO-GA. Water Resour. Manag. 2013, 27, 3525-3540. [CrossRef]

42. Huang, X.; Zhu, X.; Lian, Y.; Fang, G.; Zhu, L. The Optimal Operation of Multi-reservoir Floodwater Resources Control Based on GA-PSO. In Proceedings of the 2015 AGU Fall Meeting Abstracts, San Francisco, CA, USA, 14-18 December 2015.

43. Hosseini, S.; Al Khaled, A. A survey on the imperialist competitive algorithm metaheuristic: Implementation in engineering domain and directions for future research. Appl. Soft Comput. 2014, 24, 1078-1094. [CrossRef]

44. Hosseini-Moghari, S.-M.; Morovati, R.; Moghadas, M.; Araghinejad, S. Optimum operation of reservoir using two evolutionary algorithms: Imperialist competitive algorithm (ICA) and cuckoo optimization algorithm (COA). Water Resour. Manag. 2015, 29, 3749-3769. [CrossRef]

45. Karamouz, M.; Nazif, S.; Sherafat, M.A.; Zahmatkesh, Z. Development of an optimal reservoir operation scheme using extended evolutionary computing algorithms based on conflict resolution approach: A case study. Water Resour. Manag. 2014, 28, 3539-3554. [CrossRef]

46. Karaboga, D.; Akay, B. A survey: Algorithms simulating bee swarm intelligence. Artif. Intell. Rev. 2009, 31, 61-85. [CrossRef]

47. Allen, R.G.; Pereira, L.S.; Raes, D.; Smith, M. Crop Evapotranspiration-Guidelines for Computing Crop Water Requirements-FAO Irrigation and Drainage Paper 56; FAO: Rome, Italy, 1998; Volume 300, p. D05109.

48. Doorenbos, J.; Pruitt, W. Guidelines for Predicting Crop Water Requirements, Irrigation and Drainage Paper No. 24; FAO: Rome, Italy, 1977.

49. Steduto, P.; Hsiao, T.C.; Fereres, E.; Raes, D. Crop Yield Response to Water; FAO: Rome, Italy, 2012; Volume 1028.

50. Alizadeh, A.; Kamali, G. Crops Water Requirements in Iran; Emam Reza University Press: Mashhad, Iran, 2008.

51. Ghahraman, B.; Sepaskhah, A.R. Linear and non-linear optimization models for allocation of a limited water supply. Irrig. Drain. 2004, 53, 39-54. [CrossRef]

52. Lopez, G.; Larrigaudière, C.; Girona, J.; Behboudian, M.H.; Marsal, J. Fruit thinning in 'Conference' pear grown under deficit irrigation: Implications for fruit quality at harvest and after cold storage. Sci. Hortic. 2011, 129, 64-70. [CrossRef]

53. Meyer, S.J.; Hubbard, K.G.; Wilhite, D.A. A crop-specific drought index for corn: I. Model development and validation. Agron. J. 1993, 85, 388-395. [CrossRef]

54. Thakur, A.; Singh, Z. Responses of 'Spring Bright'and 'Summer Bright'nectarines to deficit irrigation: Fruit growth and concentration of sugars and organic acids. Sci. Hortic. 2012, 135, 112-119. [CrossRef]

55. Sivanandam, S.; Deepa, S. Introduction to Genetic Algorithms; Springer Science \& Business Media: Berlin, Germany, 2007.

56. Pham, D.; Ghanbarzadeh, A.; Koc, E.; Otri, S.; Rahim, S.; Zaidi, M. The Bees Algorithm-Technical Report; Manufacturing Engineering Centre, Cardiff University: Cardiff, UK, 2005.

57. Ghodousi, M.; Alesheikh, A.A.; Saeidian, B.; Pradhan, B.; Lee, C.-W. Evaluating Citizen Satisfaction and Prioritizing Their Needs Based on Citizens' Complaint Data. Sustainability 2019, 11, 4595. [CrossRef]

58. Pham, D.T.; Ghanbarzadeh, A.; Koç, E.; Otri, S.; Rahim, S.; Zaidi, M. The bees algorithm-A novel tool for complex optimisation problems. In Intelligent Production Machines and Systems; Elsevier: Amsterdam, The Netherlands, 2006; pp. 454-459.

59. Eberhart, R.; Kennedy, J. A new optimizer using particle swarm theory. In Proceedings of the Sixth International Symposium on Micro Machine and Human Science, Nagoya, Japan, 4-6 October 1995; pp. 39-43.

60. Heppner, F.; Grenander, U. A stochastic nonlinear model for coordinated bird flocks. Ubiquity Chaos 1990, 233, 238.

61. Saeidian, B.; Mesgari, M.; Pradhan, B.; Ghodousi, M. Optimized Location-Allocation of Earthquake Relief Centers Using PSO and ACO, Complemented by GIS, Clustering, and TOPSIS. ISPRS Int. J. Geo Inf. 2018, 7, 292. [CrossRef]

62. Sameen, M.I.; Pradhan, B. A two-stage optimization strategy for fuzzy object-based analysis using airborne LiDAR and high-resolution orthophotos for urban road extraction. J. Sens. 2017, 2017, 6431519. [CrossRef] 
63. Samsami, R. Comparison between Genetic Algorithm (GA), Particle Swarm Optimization (PSO) and Ant Colony Optimization (ACO) Techniques for NO Emission Forecasting in Iran. World Appl. Sci. J. 2013, 28, 1996-2002.

64. Eberhart, R.C.; Shi, Y. Comparing inertia weights and constriction factors in particle swarm optimization. In Proceedings of the 2000 Congress on Evolutionary Computation. CEC00 (Cat. No. 00TH8512), La Jolla, CA, USA, 16-19 July 2000; pp. 84-88.

65. Atashpaz-Gargari, E.; Lucas, C. Imperialist competitive algorithm: An algorithm for optimization inspired by imperialistic competition. In Proceedings of the 2007 IEEE Congress on Evolutionary Computation, Singapore, 25-28 September 2007; pp. 4661-4667.

66. Ghodousi, M.; Alesheikh, A.A.; Saeidian, B. Analyzing public participant data to evaluate citizen satisfaction and to prioritize their needs via K-means, FCM and ICA. Cities 2016, 55, 70-81. [CrossRef]

67. Saeidian, B.; Mesgari, M.S.; Ghodousi, M. Evaluation and comparison of Genetic Algorithm and Bees Algorithm for location-allocation of earthquake relief centers. Int. J. Disaster Risk Reduct. 2016, 15, 94-107. [CrossRef]

68. Opricovic, S.; Tzeng, G.-H. Compromise solution by MCDM methods: A comparative analysis of VIKOR and TOPSIS. Eur. J. Oper. Res. 2004, 156, 445-455. [CrossRef]

69. I.A.A.C. Comprehensive. Available online: http://climatology.ir/?p=11453 (accessed on 20 May 2015).

70. Rahab, A. Study Phase Reports of Mirza Khanlu Dam; Arkan Rahab: Zanjan, Iran, 2008.

71. Doorenbos, J.; Kassam, A. Yield response to water. Irrig. Drain. Pap. 1979, 33, 257.

72. Najarchi, M.; Kaveh, F.; Babazadeh, H.; Manshouri, M. Determination of the yield response factor for field crop deficit irrigation. Afr. J. Agric. Res. 2011, 6, 3700-3705.

73. Office, Z.A. Official Reports for Crops. Available online: http://www.agrizanjan.ir/index.php?option=com content\&view=article\&id=524:2014-08-21-07-14-21\&catid=45\&Itemid=232 (accessed on 20 May 2015).

74. Khan, M.I. Optimal Water Allocation for Rice Production under Climate Change. Ph.D. Thesis, School of Economics, La Trobe University, Melbourne, Australia, 2013.

75. Ahmad, I.; Zhang, F.; Liu, J.; Anjum, M.N.; Zaman, M.; Tayyab, M.; Waseem, M.; Farid, H.U. A linear bi-level multi-objective program for optimal allocation of water resources. PLoS ONE 2018, 13, e0192294. [CrossRef]

76. Berbel, J.; Gutiérrez-Martín, C.; Expósito, A. Impacts of irrigation efficiency improvement on water use, water consumption and response to water price at field level. Agric. Water Manag. 2018, 203, 423-429. [CrossRef]

77. Marchant, D.; García Peña, A.; Tamas, M.; Harou, J. Simulating Water Allocation and Cropping Decisions in Yemen's Abyan Delta Spate Irrigation System. Water 2018, 10, 121. [CrossRef]

78. Yu, Y.; Yu, R.; Chen, X.; Yu, G.; Gan, M.; Disse, M. Agricultural water allocation strategies along the oasis of Tarim River in Northwest China. Agric. Water Manag. 2017, 187, 24-36. [CrossRef]

79. Zhang, C.; Engel, B.A.; Guo, P. An Interval-based Fuzzy Chance-constrained Irrigation Water Allocation model with double-sided fuzziness. Agric. Water Manag. 2018, 210, 22-31. [CrossRef]

80. Zhang, D.; Guo, P. Integrated agriculture water management optimization model for water saving potential analysis. Agric. Water Manag. 2016, 170, 5-19. [CrossRef]

81. Zhang, F.; Zhang, C.; Yan, Z.; Guo, S.; Wang, Y.; Guo, P. An interval nonlinear multiobjective programming model with fuzzy-interval credibility constraint for crop monthly water allocation. Agric. Water Manag. 2018, 209, 123-133. [CrossRef]

82. Wolpert, D.H.; Macready, W.G. No free lunch theorems for optimization. IEEE Trans. Evol. Comput. 1997, 1, 67-82. [CrossRef]

(C) 2019 by the authors. Licensee MDPI, Basel, Switzerland. This article is an open access article distributed under the terms and conditions of the Creative Commons Attribution (CC BY) license (http://creativecommons.org/licenses/by/4.0/). 